\title{
Enquête
}

Archives de la revue Enquête

1 | 1985

À propos des cultures populaires

\section{Alternance et ambivalence}

\section{(2) OpenEdition}

1 Journals

Édition électronique

URL : http://journals.openedition.org/enquete/39

DOI : 10.4000/enquete.39

ISSN : 1953-809X

Éditeur :

Cercom, Éditions Parenthèses

Édition imprimée

Date de publication : 2 avril 1985

\section{Référence électronique}

"Alternance et ambivalence », Enquête [En ligne], 1 | 1985, mis en ligne le 26 juin 2013, consulté le 30 avril 2019. URL : http://journals.openedition.org/enquete/39 ; DOI : 10.4000/enquete.39

Ce document a été généré automatiquement le 30 avril 2019. 


\section{Alternance et ambivalence}

J.-C. PASSERON.- Voulant montrer à quoi tenait, dans la question posée à la sociologie par la description des cultures populaires, l'oscillation du discours sociologique entre l'«analyse culturelle» (qui doit accorder la pleine autonomie symbolique à son objet) et l'« analyse idéologique » (qui doit scruter les propriétés qu'il tient de ses fonctions dans le fonctionnement $d u$ rapport de domination), peut-être avons-nous, dans la séance précédente, trop oscillé nous-mêmes entre les profits descriptifs de l'une et l'autre approche, entre les mises en garde croisées contre leurs cécités complémentaires, entre les mérites théoriques de l'«alternance» et de l'«ambivalence» comme concepts régulateurs des relations entre les deux types d'analyse? Un schéma pourrait, à ce point, fixer quelque peu les mots que nous utilisons dans le débat, c'est-à-dire les opérations, maîtrisées ou non, qui lient entre eux les concepts. N'en attendons pas plus que de comprendre ce que nous faisons et ce que nous omettons quand nous faisons nos choix de description et d'analyse: graphismes, formalismes et modèles ne sauraient tenir lieu d'une théorie, que nous ne vantons pas de posséder - précisons-le. 


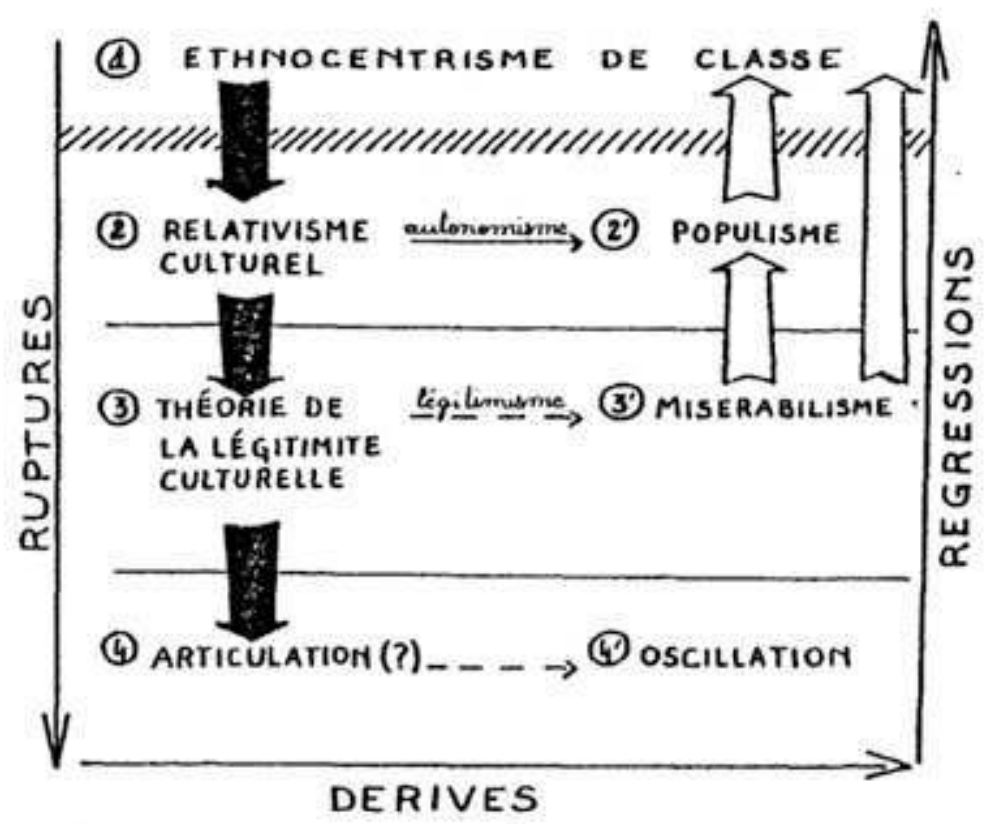

\section{Les ruptures}

De 1 à 2: c'est de la rupture avec l'ethnocentrisme comme pratique spontanée de description que procède toute entreprise scientifique d'analyse d'une société ou d'une culture. En deçà de cette première prise de distance - par quelque méthodologie ou quelque déplacement théorique qu'elle s'opère - n'existe évidemment que paraphrase de l'auto-centration sociale du locuteur («sociologie spontanée», curiosité touristique, «sentiment linguistique » etc.), contresens et faux-sens sur l'altérité sociale solidement cimentés, par leurs fonctions sociales, en systèmes de sens. Cela est vrai de toute ethnologie et de toute sociologie quel que soit son objet; mais l'existence de cette première rupture est sans doute plus aiguë et mentalement plus difficile quand l'objet est un symbolisme dominé. D'un symbolisme dominant, on peut encore, sans trop se déprendre de ses valeurs et de ses schèmes, dire quelque chose qui fasse distance et connaissance par le travail ou la méthode d'analyse. D'un symbolisme dominé qui ne produit pas ses savants indigènes, le savant à la fois exogène et ethnocentrique est inconcevable puisqu'il ne construirait plus que des dénis de sens. Ici, qu'il s'agisse de sociétés soumises ou de classes dominées, l'abolition de la proximité complice au dominant constitue le minimum épistémologique vital. L'ethnocentrisme ou le racisme de classe ne sont pas moins puissants ni moins pernicieux que leurs homologues sans adjectifs contre lesquels l'ethnologie a dû mobiliser et doit remobiliser sans cesse un relativisme culturel sans concessions ni atténuations. C'est donc au relativisme culturel que revient la tâche du premier acte de justice descriptive qui consiste à créditer les cultures populaires du droit d'avoir leur sens. Son opération propre, c'est de les prendre au sérieux en tant que cultures, c'est-à-dire de commencer par le commencement, l'apprentissage de la langue dans laquelle elles disent ce qu'elles ont à dire, quand on parvient à oublier ce qui se dit sur elles dans une autre langue. Pour donner toutes ses 
chances à cette écoute, le relativisme culturel doit donc nécessairement pratiquer une autonomisation plus artificielle et plus décisoire que dans le cas des cultures lointaines ou passées dont les supports sont des sociétés et non des classes, puisqu'il doit pour mener à bien son ethnologie mimétique, traiter les cultures dominées comme si elles ne l'étaient pas. Non pas certes comme des cultures dominantes, mais sa tâche est bien de leur prêter par hypothèse tout ce dont disposent d'emblée celles-ci : son seul souci n'est pas de trop prêter, mais d'éviter de soustraire.

3 De 2 à 3 : c'est donc d'une seconde rupture, celle qui remet en cause la fiction de cette autonomie, que procède la théorie de la légitimité culturelle et plus généralement toute démarche puisant le principe de ses descriptions dans le réalisme sociologique qui interdit de mettre sous le boisseau les rapports de force, les lois de l'interaction inégale liant entre elles les classes d'une même société : on ne peut, sans mutiler la description, soustraire à l'ordre symbolique les effets du rapport de domination qui, dans une société de classes, organisent cet ordre en "ordre culturel légitime"; on ne peut laisser au relativisme culturel le soin de tout dire des rapports entre les cultures portées par des classes qui nourrissent leurs interactions symboliques de ne pas le pratiquer. Pour faire justice de l'injustice interprétative que l'ethnocentrisme faisait aux cultures populaires, le relativisme culturel doit commettre à leur égard une injustice descriptive symétrique, en oubliant, avec les effets de la domination, tout ce qui dans les pratiques dominées ne se laisse pas oublier longtemps. Ne revenons pas sur ce que ce principe permet d'ajouter à la construction de ses objets par la sociologie de la culture. Ni non plus sur ce qu'il soustrait à la description des cultures populaires en les construisant sur l'hypothèse de leur participation a un ordre de la légitimité culturelle : les instruments qui construisent une sociologie du consentement à l'ordre, de la reconnaissance de la légitimité, ne sont pas des opérateurs commodes pour dire ce qui est de l'ordre de la non-reconnaissance, ce qui est d'un autre ordre, même s'il ne s'agit que d'un « ordre partiel ».

4 De 3 à 4 : il faut donc, dès qu'on se pose ce problème, s'apprêter à une troisième rupture qui introduirait dans le travail et le discours sociologiques une articulation explicite entre les moyens et les acquis de description que les styles d'analyse 2 et 3 ne procurent que séparément ou dans un mixage qui ne dit pas son principe...

C. GRIGNON.- Vous avez dit « rupture » ? Nous voilà bien si l'on ne peut plus compter sur la théorie de la légitimité.

6 J.-C. PASSERON.- Le terme de "rupture » n'est pas si solennel. Ne confondons pas travail sociologique et histoire du surréalisme où la moindre « rupture » avec le voisin de palier suscite aussitôt un Manifeste. Il ne s'agit pas de désigner à quelque sociologie ou à quelque sociologue que ce soit l'objectif, sans doute irréalisable, du hat-trick (de la passe de trois), ici le coup des trois ruptures réalisées dans la foulée, mais seulement de dessiner la topographie commandée par trois systèmes d'axiomes, pas facilement compatibles, entre lesquels chacun fait ce qu'il peut. Ou, si l'on veut, il ne s'agit ici que de débrouiller des énoncés empiriques qui ne demandent qu'à s'embrouiller : quand on a pu distinguer une mèche d'une autre, on met un peigne entre les deux pour s'y retrouver. Une rupture épistémologique, ce n'est pas un gain qu'on engrange, mais une clarification qui ne se maintient que si on la recommence sans cesse dans la patience du travail empirique et de la formulation: telle rupture que vous venez d'opérer dans une phrase, vous l'avez déjà reperdue dans la suivante ; on dirait même que le langage et, plus encore, l'écriture font ça tous seuls : reprendre comité en se jouant l'effet de connaissance qu'ils 
semblent avoir concédé à perpétuité. Nous y venons avec les dérives et les régressions que l'espace du schéma nous présente orthogonalement.

\section{Les dérives}

7 On peut voir dans les faits, c'est-à-dire dans les analyses faites par sociologues et anthropologues, à quelle idéologie descriptive prédispose chacune des deux constructions d'objet : le populisme dans un cas par le glissement de l'autonomisation méthodologique à l'oubli de ce qu'elle opère (autonomisme), le misérabilisme dans l'autre par l'oubli de ce qui échappe à l'ordre symbolique que construit la théorie de la légitimité culturelle (légitimisme). Ce n'est pas notre propos d'entrer ici dans la sociologie des deux idéologies qui représentent le point ultime de chaque dérive : populisme et misérabilisme possèdent chacun des formes, des connotations descriptives, des fonctions et des groupes-supports différents et multiples; il leur est même souvent arrivé de permuter leurs segments descriptifs ou leurs porte-parole, tant est complexe et mouvant l'enjeu qu'engagent dans la description du Peuple les diverses fractions d'intellectuels (dont font partie les sociologues: il sommeille toujours un idéologue en tout sociologue môme le plus professionnalisé). Mais il est trop simple de croire qu'il suffirait d'être aussi sociologue que possible pour se garder de toute dérive idéologique, que le professionnalisme des instruments et des mesures a réponse à tout. Il faut aussi se demander, si l'on veut contrôler une dérive idéologique vers ou la problématique proprement scientifique dans laquelle on travaille fait dériver. Autrement dit, il y a dans la structure des constructions d'objet qu'instaurent les différentes ruptures une logique qui facilite une dégradation idéologique plutôt qu'une autre.

Les régressions

9 Si l'ethnocentrisme constitue l'organisation première de toute perception de l'altérité sociale, le «sol natal» de toute description, on comprend immédiatement que tous les chemins ramènent à cette Rome herméneutique. Dès qu'elle a commencé à se dégrader en populisme ou en misérabilisme, la description des cultures populaires tend toujours à régresser vers l'ethnocentrisme de classe qui, sachant tout d'avance, constitue le bouchetrou sémantique le plus commode, le mieux partagé aussi puisque, pour paraphraser à l'envers l'ironie cartésienne sur le bon sens, ceux qui le pratiquent le mieux sont aussi les plus enclins à s'en croire dépourvus. Il suffit d'un moment d'inattention pour voir pulluler ce raton-laveur ou, plus sérieusement, il suffit de relâcher, dans un raisonnement ou un constat, le contrôle de renonciation pour que la place laissée vide se remplisse immédiatement de ce surplus de sens. Quand le populiste s'émerveille de découvrir des trésors symboliques dans une culture populaire où le bourgeois comme le misérabiliste ne verraient que des pénuries, la bonne conscience du financier à l'égard du savetier transfuge n'est jamais bien loin derrière sa description : "puisque leur univers est aussi riche que le nôtre - et même plus riche, voyons ! - qu'est-il besoin de leur proposer d'en changer? » Et quand le misérabiliste croit avoir assez rendu aux pauvres en rendant compte - comptable scrupuleux des inégalités et censeur sévère des privilèges - de toutes les différences comme autant de manques ou d'exclusions c'est le paternalisme qui montre le bout de son nez : après une telle litanie des non-avoirs, le tour est fait de tous les avoirs susceptibles d'entrer dans un bilan de comptabilité symbolique, rien de plus que le bilan de l'ordre légitime. Bref, l'ethnocentrisme de classe est toujours à portée de main. C'est ce que n'exprime pas le schéma soumis à la loi de l'espace homogène du plan, 
qui suggère qu'on est d'autant plus prémuni contre l'ethnocentrisme de classe qu'on s'en est affranchi par plus de ruptures. Il n'en est évidemment rien ; pour toute description (2, 3,4 et a fortiori 2', 3', 4'), le chemin qui y ramène est toujours aussi direct et aussi rapide.

De l'articulation entre les deux constructions d'objet qu'opèrent la théorie de la légitimité culturelle et le culturalisme appliqué aux cultures populaires je laisse à débattre en quels termes elle pourrait être plus et autre chose qu'oscillation ou repentirs successifs et contradictoires. La dérive propre de la double exigence à laquelle soumet la troisième rupture est évidemment d'engendrer un type de description où là conscience du " manque à décrire » ne déclencherait qu'un déclic compensatoire : les compensations se règlent souvent, on le sait, en monnaie d'imaginaire. Le repentir d'un excès de légitimisme est plus souvent complaisance au stéréotype populiste que mise en œuvre des exigences propres du relativisme culturel (culturalisme); et d'un excès de culturalisme plus souvent déploration misérabiliste des privations ou des exclusions populaires que mise en œuvre explicite du concept de légitimité. Pour ouvrir le débat disons seulement qu'articuler les problématiques du culturalisme et de la légitimité culturelle en termes d' alternance ou d'ambivalence n'affronte pas aux mêmes tâches la sociologie des cultures populaires.

11 Faire de l'hypothèse d'alternance le principe régulateur de la description des pratiques populaires conduit assez facilement à des protocoles d'enquêtes. Il suffit de distinguer et de multiplier les occasions de distinguer : ici (dans tel domaine de pratique, dans tel sousgroupe, à tel moment, dans telle situation d'interaction) c'est comme ci (autonomie symbolique); là c'est comme ça (hétéronomie symbolique). Il y a des «terrains » des « interactions ", des «strates » des classes populaires où la pratique s'avère sensible aux indicateurs de l'intériorisation de la légitimité culturelle (autodépréciation, honte culturelle, dénégation, imitation, compensation, etc.); il y en a d'autres où ces indicateurs restent parfaitement muets, où les compteurs de la reconnaissance de la légitimité sont à zéro et où, inversement, la cohérence des pratiques se laisse aisément reconstruire comme s'il s'agissait d'une culture autonome, comme si on parlait des Trobriands. C'est faire une hypothèse un peu simple, mais c'est déjà s'astreindre à un surcroît de sociologie empirique, s'obliger à multiplier les terrains d'observation, et les stratifications sociales, à les contraster, à les construire en protocoles comparatifs complexes. Ce n'est déjà pas si mal à propos d'un problème comme celui de la domination où les énonciations sont volontiers d'ambition universelle ou totalitaires: les "classes dominées ", c'est un concept guère plus empirique que celui de " prolétariat » chez Marx.

Mais est-ce suffisant? Ne rencontre-t-on pas immédiatement des pratiques, des discours, des symbolismes populaires qui se laissent construire indifféremment, dans les énoncés descriptifs, comme faits d'autonomie ou faits d'hétéronomie? L'hypothèse de l'ambivalence de tout symbolisme et de toute pratique de classe dominée permet de poser cette question dans toute sa généralité. Convenons pour fixer les opérations dans des mots, d'appeler « analyse idéologique » (au sens strict d'analyse fonctionnaliste externe) la description sociologique qui s'opère en interprétant les formations symboliques (verbales ou pratiques) par référence aux fonctions qu'elles assument dans les rapports de domination; et « analyse culturelle » la description qui opérant à partir du concept de " système » interprète les éléments (les « traits culturels ») par référence à la cohérence interne et autonome du système. La distinction entre les deux formes d'analyse est du même ordre que celle que mettait Saussure entre "linguistique externe" et «linguistique interne». On pourrait dire ici «culturologie externe» et «culturologie 
interne ». Ce sont évidemment les mêmes faits de langue auxquels s'appliquent, en les construisant différemment, les deux approches linguistiques. De même, ce sont, bien sûr, deux lectures différentes du même texte symbolique (au sens où toute réalité sociale ou historique peut être décrite comme signifiante par une opération de mise en relation) qu'opèrent l'analyse idéologique et l'analyse culturelle; elle n'ont pas pour objet deux morceaux différents de la réalité. Les formations symboliques (pratiques, institutions, systèmes d'idées) ne sont pas des fromages que l'on pourrait découper en parts réellement distinctes, en " éléments idéologiques » et en "éléments culturels » existant partes extra partes (éléments appelant per se des mises en relation de type A' ou B' et éléments exclusivement justiciables de mises en relation de type A ou B, selon le schéma 2, p. 15). Pas davantage - disons-le en passant contre une épistémologie réaliste que le marxisme althussérien partage avec le positivisme schumpétérien - qu'on ne saurait isoler, réellement, du point de vue de la pertinence assertorique, des "éléments idéologiques" et des "éléments scientifiques" dans un discours, i. e. des énoncés idéologiques qui révéleraient leurs sens extra-scientifique du simple fait qu'ils se prêtent à la sociologie (marxiste ou non) de la connaissance et des énoncés scientifiques que leur vérité soustrairait à toute mise en rapport avec des fonctions sociales. L'analyse culturelle n'est pas non plus une partie de l'analyse idéologique ou vice versa. Les marxistes ont longtemps considéré que l'usage du concept de «culture » mutilait le plein exercice de l'analyse idéologique préposée à la tâche de faire avouer à toute réalité sociale son sens « dernier » de réalité de classe. En France, dans les années 1970, certains marxistes, plus conciliateurs, ne voulurent voir dans la totale extériorité réciproque de l'analyse marxiste des idéologies et de l'analyse anthropologique des cultures qu'un malentendu lexicologique : à les entendre, il suffisait pour le dissiper, d'apercevoir que les marxistes appellent "idéologique» ce que, par une sorte d'aveuglement corporatiste bien pardonnable, sociologues et ethnologues appellent «culture » (au sens de la Wertanalyse wébérienne ou de l'anthropologie culturelle américaine). C'était faire piètre mesure de ce qu'engagent les constructions différentes du même « objet » symbolique. L'épistémologie ne peut se payer de ces réconciliations diplomatiques.

L'hypothèse de l'ambivalence significative des réalités symboliques oblige, au contraire, à admettre pleinement dans l'analyse et l'interprétation les droits de la double lecture. Si l'on veut raffiner, il ne suffit d'ailleurs pas de distinguer, pour les enfermer dans des univers de sens sans communications, les deux significations d'un même comportement que construisent l'analyse culturaliste et l'analyse de l'ordre symbolique dominant. Il faut aussi se servir des deux descriptions pour décrire les rapports sociaux et symboliques par lesquels chacun des deux sens retourne l'autre, en tirant son mode d'efficacité propre de ce retournement même. Il ne s'agit pas, par exemple, de renvoyer dos à dos une description culturaliste des comportements populaires "d'indifférence à la politique » comme forme positive du contrôle culturel de l'incontrôlable (Hoggart) et une description idéologique des mêmes comportements comme effet fonctionnel de la domination subie ("résignation », acceptation, démobilisation); mais d'en venir à décrire les services propres que le sens culturel rend à l'exercice de la domination, et qu'il ne peut lui rendre, à son corps défendant, qu'en tant qu'élément d'une cohérence culturelle dont la positivité ne se réduit jamais au sens idéologique; en même temps que l'on doit décrire les conditions faites par la domination à l'exercice de la cohérence culturelle pour la comprendre complètement. Pour le problème qui nous occupe, cela consiste à accepter de considérer tout «trait " populaire comme un palindrome à double sens, i. e. comme une séquence de lettres dont le sens qui saute d'abord aux yeux peut tout aussi bien devenir 
autre, dès qu'on décide de le prendre par l'autre bout. Vous lisez «LES ELEVES »; et c'est une bonne lecture, mais c'est aussi faute de prendre la décision de lire la même séquence de droite à gauche «(à) EVE|LE SEL ». Évidemment, sur mon palindrome douteux une lecture est un peu meilleure que l'autre qui laisse une lettre (le à) hors du sens. Mais l'imperfection pourrait aussi désigner un problème que pose l'articulation de l'interprétation des cultures populaires en termes d'alternance et d'ambivalence: les ambivalences ne sont jamais parfaites. En chaque cas, il reste à se demander - ni la méthodologie ni la théorie n'en sont commodes - si un sens de la lecture n'est pas un peu plus explicatif que l'autre. eux-mêmes une position ambivalente qu'on voit le mieux l'ambivalence de tout discours - y compris le discours à visée scientifique - qui essaie de se prononcer sur la relation inégale entre les cultures. Voici par exemple un texte de Georges Navel, dont, à l'inverse de ce qu'écrit un critique du Monde, il n'est pas indifférent de savoir qu'il a été non seulement écrivain, mais aussi ajusteur, terrassier, maçon, camelot, jardinier, apiculteur, correcteur de presse ${ }^{1}$.

J.-C. PASSERON.- Trouvez-vous que ce texte nous simplifie la tâche en ce qu'il nous fournit des instruments de description de l'ambivalence, utilisables par le sociologue ? Ou est-ce qu'il la complique en surdéterminant l'ambiguïté objective de la relation entre les cultures par l'ambiguïté constitutive de toute reconstruction littéraire de la réalité ? exemplaire dans la mesure où il se prête - bonne illustration de l'ambivalence - à des lectures antagonistes. On peut le déchiffrer d'une manière résolument, et même à un premier degré, platement légitimiste, sans même vouloir reconnaitre l'ironie qu'il enferme : vous voyez bien que Navel reconnaît que les voyageurs de première classe sont distingués puisqu'il dit « distinction ». Un lecteur légitimiste plus subtil dira que c'est un texte écrit en réaction contre, mais toujours par référence à la culture dominante, que le double jeu que Navel a voulu jouer en jouant sur les mots se retourne contre lui, et qu'en définitive il reconnaît la légitimité des dominants par le seul fait qu'il emprunte, pour les écrire, les mots des dominants - et il n'y en a pas d'autres, ils ont tous les mots et tous les usages des mots - pour décrire les dominants ; bref, que la partie est perdue, que les jeux sont faits à partir du moment où l'ouvrier Navel s'est risqué dans le jeu littéraire. À l'inverse, on peut dire, lecture contestataire : voyez un peu comme Navel, en racontant comment il renverse la situation et retourne contre les dominants les affronts que ceux-ci lui destinent (vous m'ignorez, je vous ignore ; vous êtes de glace, je jette un froid, etc.), détourne et retourne le langage des dominants, montre que « distinction » signifie, de son point de vue, "vulgarité » ("veau d'or »-» petit goret»), et détourne en fin de compte le jeu littéraire lui-même. De même, on peut insister soit sur l'exclusion symbolique dont Navel est l'objet de la part des voyageurs de première classe, en montrant qu'il est bien forcé de la reconnaître (et de reconnaître ce qui l'exclut), même et surtout s'il essaie de revendiquer et de retourner cette exclusion, ou au contraire, sur l'expérience de l'autonomie du mode de vie populaire, et du système de valeurs associé à celui-ci, sur laquelle il se fonde pour rejeter et annuler ce qui l'exclut. 
R.-M. LAGRAVE.- C'est un texte trop construit ; Navel commence par décrire la manière dont il se laisse intimider (dont il reconnaît la légitimité de ce qui l'humilie), puis la manière dont il essaie de réagir (de résister) ; après avoir décrit il commence à analyser, à décortiquer, à retourner la chose... C'est de la littérature, quoi !

21 J.-C. PASSERON.- C'est en tout cas un texte écrit dont on ne sait pas très bien sur quel ton il serait dit ; par exemple, y a-t-il ou non des guillemets à « distinction »? Pour ne rien dire des « points d'ironie » ou de gouaille. Mais à la fin des fins, que veut-on dire quand on dit d'un texte que "c'est de la littérature "? Dans quelle mesure échappe-t-il à la sociologie de la littérature? Le jeu littéraire auquel il joue aurait-il un sens s'il ne se référait à une expérience sociale? Pour en revenir à la question de la symétrie, le problème théorique qu'impose au lecteur le texte de Navel ne semble être celui-ci : les dominés peuvent-ils faire autre chose, dans un discours décrivant et contestant la domination que retourner les mots de la description dominante? Dans la mesure où Navel doit feindre d'employer ingénument les mots des « autres " pour pouvoir les subvertir par l'inversion ironique, ne révèle-t-il pas que la dévaluation des valeurs dominantes obéit en l'occurrence à la logique de la formation réactionnelle? Jouer à retourner contre eux le langage des dominants est encore une manière de reconnaître qu'il faut bien se résoudre à employer ce langage puisque c'est le langage dominant qui tient lieu de métalangage de l'évaluation des valeurs des uns et des autres. Dissymétrie totale : les dominants ne se volent jamais imposer la tâche sociale de retourner un langage des " qualités » et des "qualifications » qui, pour eux, tourne déjà dans le «bon » sens - celui de leur poil.

C. GRIGNON.- Effectivement, Navel décrit la manière dont il essaie de réagir à une situation qui lui a été imposée (train bondé, pas de place ailleurs qu'en première) et qui l'expose, objectivement, à perdre la face, à subir une succession d'intimidations et d'humiliations en provenance des occupants légitimes des compartiments de première classe (ou des gardiens de l'ordre ferroviaire). Ce faisant, il reconnaît que ses évaluations propres "savent» les valeurs des gens d'en face, qu'il ne peut pas se mettre à les ignorer comme ils l'ignorent, sur le mode de l'évidence spontanée. Mais il faut remarquer que Navel se définit négativement non seulement par rapport à la certitudo sui autistique des dominants mais aussi par rapport à l'autonomie non moins inentamable du gitan (« je ne suis pas à l'aise comme le serait un bohémien »), qui, elle, est le produit d'une altérité culturelle radicale et de la méconnaissance totale des valeurs des dominants. Incarnation du thème de l'innocence adamique, le bohémien représente évidemment une situationlimite; et il est vrai qu'une des aberrations courantes du populisme consiste à accorder d'emblée à la culture populaire l'autarcie symbolique complète dont ne s'approchent que des mini-cultures marginales et/ou déviantes. Mais faut-il être plus exigeant à l'égard de la littérature qu'on ne l'est d'habitude à l'égard de la sociologie (qui ne s'astreint pas toujours à ne retenir que des types idéaux qui atteignent un seuil minimum de réalité statistique), et lui demander de marquer clairement la distance qui sépare le cas limite du cas modal?

Je crois que l'intérêt de ce passage (dans lequel on peut voir aussi bien une simple " narration » qu'un texte très travaillé et trop habile) vient de ce qu'il condense sans avoir l'air d'y toucher toute une expérience sociale : ce qui " autorise » Navel à écrire, ce qui lui permet de trouver d'emblée le "ton» juste, c'est l'analogie profonde entre l'anecdote qui sert de trame au récit et sa propre trajectoire de déraciné (le train ramène Navel de son pays natal à Paris) et de déclassé-surclassé, qui n'est pas parvenu à trouver sa place dans sa «classe » d'origine et qui ne la trouve pas non plus dans la classe 
supérieure où il s'est risqué, sans l'avoir vraiment voulu, par le biais de la littérature. De ce point de vue, Navel produit une chimère qui me paraît sociologiquement utilisable : il parvient à nous donner une idée de ce que ressentirait un chemineau en situation non voulue de contact avec des « gens de la haute » si par impossible il était aussi écrivain.

J.-C. PASSERON.- Va pour la littérature! Mais peut-on assigner à la sociologie la tâche de parler des choses de la domination dans un langage neutre ? Y a-t-il des mots socialement neutres ? Peut-on concevoir des catégories de la description où le choix entre les mots du langage des dominants - avec les évaluations qu'ils portent - et les mots du langage des dominés puisse être esquivé ? Le relativisme culturel qui nous $y$ encourage ne nous condamne-t-il pas à la tâche, culturellement et linguistiquement impossible, de trouver un langage de description qui ne ferait injustice interprétative à aucune pratique, injure ou hommage éthique à nulle classe sociale - pour ne rien dire des adjectifs qualificatifs par où passe l'essentiel du message? Hors le cas des cultures vraiment étrangères au descripteur, comme celles où l'ethnologie peut trouver dans la parfaite extériorité réciproque de la " théorie indigène » et du regard ethnocentrique du colonisateur ou du voyageur une distance première qui fonde l'autonomie de son langage de description par rapport à l'un et l'autre codes culturels (encore en a-t-on douté), la description anthropologique des valeurs, qui ne peut éluder dans renonciation le choix d'un « rapport aux valeurs » (au sens de Weber), reste toujours prisonnière dans les sociétés de classes des échos d'une domination symbolique qui marque dans le langage - et donc pour le lecteur, quand encore le sociologue n'en joue pas - jusqu'aux mots qu'elle reconstruit en concepts (" légitimité ", « distinction », « vulgarité », « compétence », etc.). Navel met le doigt sur ce que tend à dissimuler l'illusion positiviste de la neutralité du langage " scientifique » de l'analyse culturelle, à savoir que le rapport aux valeurs modelé par une domination symbolique qui organise les pratiques de toute une société est toujours plus intimement inscrit dans le langage que les rapports pratiques aux valeurs qui sont toujours pour l'essentiel des rapports muets: le rapport dominant aux valeurs (dominantes ou dominées) commande d'autant plus efficacement la formulation du sens des valeurs, qu'il revient, au galop, plus «naturellement » dans l'expression, y compris chez le sociologue qui se veut relativiste ou l'intellectuel en quête de transgression. Le retournement en trompe-l'œil de la perspective dominante que le jeu littéraire avec l'envers et l'endroit des mots permet à Navel illustre $a$ contrario que le retournement linguistique d'une domination sociale inscrite dans le langage constitue bien la quadrature du cercle pour un projet d'énonciation scientifique.

C. GRIGNon.- Tout le monde se demande si le texte de Navel est un texte d'écrivain, un témoignage d'ouvrier, un document, une reconstitution quasi sociologique, l'un ou l'autre ou tout cela à la fois. Mais c'est peut-être en faisant voir ce que la littérature dérobe à la sociologie que le texte de Navel rend service à cette dernière, puisqu'il lui montre ce qu'elle ne peut dérober à la littérature. Du reste la lecture comparée d'écrivains populaires et des textes consacrés par les sociologues à la culture populaire en convainc facilement.

R.-M. LAGRAVE.--Je crois que le texte de Navel est faussement naïf ce n'est pas un bon exemple d'attitude populaire dans la mesure où G. Navel, même dans la littérature populiste ou prolétarienne de son temps est considéré comme quelqu'un qui fait partie de la culture légitime. Ce n'est pas n'importe qui, Georges Navel! Quand on sait que ses textes ont été édités par Giono! 


\section{tra} transactions psychologiques sur la présentation de sol au lecteur que l'auteur gère tactiquement dans la description d'une inter-action sociale «tordue » afin de parfaire un effet littéraire - est, me semble-t-il, celle-ci : nous révèle-t-il quelque chose d'une logique de la résistance populaire à la domination symbolique, que l'on pourrait observer dans les comportements culturels des classes populaires aussi bien que dans le parti d'orchestration littéraire qu'en tire ici un écrivain d'origine populaire? Je crois que oui, puisqu'il met à nu le rôle joué par le mécanisme d'inversion dans toute évaluation culturelle qui doit compter, lors d'une confrontation inégale, avec une évaluation dominante c'està-dire une évaluation qui dispose de tous les moyens directs et indirects de faire sentir et de rappeler qu'elle est celle des plus torts quand il ne lui suffit plus d'apparaitre comme évaluation de « tout le monde ", c'est-à-dire comme « ordre légitime » dont l'évidence fait l'exercice plein de la domination symbolique et dont les ratés font l'affrontement culturel. Lorsque il peut percevoir l'arbitraire du rapport de domination symbolique et qu'il doit l'affronter concrètement, chaque dominé le manipule, s'il en pâtit, avec ce qu'il a sous la main. Que ce soit ici l'aptitude au jeu littéraire de la surenchère de la "distinction» et de la "vulgarité » ou ailleurs toutes les formes circonstancielles de l'affirmation de non-dépendance: le retrait dans le quant-à-soi («se faire oublier» lorsqu'on n'est pas dans les conditions où la domination vous oublie), l'auto-affirmation agressive par la provocation, la contestation ou la dérision, l'ostentation d'une contreforce politique ou économique le cas échéant... S'il ne peut en faire un texte littéraire comme Navel, le voyageur populaire égaré en première classe - ou en tel autre lieu naturel des pratiques de luxe ou de culture savante- a d'autres moyens de «faire avec », offensivement ou défensivement. En tout cas, dans une interaction ouverte de ce type, il n'a pas le choix d'ignorer une dissymétrie qui joue en sa défaveur, il ne peut avoir la conscience culturelle en paix - même et surtout si elle ne se réduit pas au sentiment de sa propre indignité - il faut qu'il justifie sa revendication de n'être pas ce qu'il sait que l'évaluation de la situation par « les autres » lui impose d'être. L'oscillation et l'ambivalence dont joue le texte de Navel dans l'évaluation monologuée de ce que valent les uns et les autres, leurs manières et leurs personnes s'observeraient donc aussi bien, mais en acte, dans les comportements quotidiens qui mettent les dominés au contact sporadique des dominants.

Mais si on prend au sérieux ce que suppose le ressort de l'inversion dans l'engendrement de la « résistance culturelle » des dominés - à savoir que la conscience de la domination subie est sont point d'appui obligé - il faut bien conclure que ce n'est pas dans les situations de confrontation inégale qu'une culture populaire laisse observer les mécanismes qui exprimeraient le mieux son autonomie de fonctionnement ; on pourrait dire aussi bien : les mécanismes qu'elle laisse jouer dans son inconscience culturelle et qui, vilipendés par les intellectuels comme "aliénation » ou par les militants ouvriers comme "résignation ", n'en demeurent pas moins les révélateurs de ce en quoi une culture dominée fonctionne encore comme culture, c'est-à-dire comme maîtrise symbolique d'une condition sociale indépendamment des rapports inégaux qu'elle entretient avec d'autres cultures. Que cette autonomie symbolique soit sociologiquement illusoire puisqu'elle suppose l'inconscience des contraintes qu'elle subit au travers d'une condition dominée, ne dispense pas de décrire les effets culturels qu'elle produit réellement. En tout cas, le 
modèle de l'autonomie symbolique, de quelque manière qu'on le compose avec le modèle de la domination symbolique n'est jamais disqualifié d'avance dans le travail de description du sociologue, sauf à abdiquer par principe (éthique ou politique) toute analyse culturelle dans le cas des cultures populaires (i. e. à revenir du schéma 2 au schéma 1 pp. 15 et 12 ou, dans le schéma 2, de rabattre toute les interprétations selon B sur les relations de type B'). Le concept de « résistance culturelle » qui met d'office l'analyse idéologique au cœur de toute analyse culturelle propose les facilités omnibus d'une clef universelle qui ici n'ouvre proprement aucune des deux boites à signifiés. Par ses aspects réactionnels la révolte symbolique que met en branle toute mise en contact de dominés avec un dispositif culturel dominant ou avec des membres et agents des classes dominantes renvoie toujours, d'une manière ou d'une autre, à la connaissance et, pour une part, à la reconnaissance, fût-elle belliqueuse, de la domination symbolique. Il est vain de scruter ces situations d'interaction ou d'affrontement en espérant y trouver, fût-ce à leur niveau le plus virulent de dévaluation des valeurs dominantes, un processus d'évaluation qui ne passerait pas, à un moment ou à un autre, par la dénégation.

C. GRIGNON.- Voilà une analyse fermement légitimiste !

31 J.-C. PASSERON.- Oui, dans la mesure, où elle convie à ne pas prendre des vessies pour des lanternes : la révolte symbolique pour l'émancipation symbolique. Non, dans la mesure où elle permet de prospecter les terrains de l'insoumission culturelle qui sont plus vastes que ceux de la révolte. Si la production de symboles et de comportements s'effectue jamais, dans les classes populaires, de manière autonome, c'est plutôt dans des conditions soustraites momentanément ou localement à l'action visible et aux effets directs du rapport de domination. C'est l'oubli de la domination, non la résistance à la domination qui ménage aux classes populaires le lieu privilégié de leurs activités culturelles les moins marquées par les effets symboliques de la domination. Si la parenthèse du dimanche, les activités insulaires de l'aménagement de l'habitat ou l'activisme décontracté de la sociabilité entre pairs permettent le mieux de saisir dans sa cohérence symbolique l'univers culturel de la vie ouvrière et citadine (ou, plus encore, l'extériorité de la vie paysanne traditionnelle par rapport aux agents et aux instances d'une domination sociale et économique dont l'espace hodologique du village n'enregistre que discontinûment les effets), c'est que ces conditions ménagent un univers soustrait à la confrontation, des moments de répit, des lieux d'altérité. Ce n'est pas un hasard si la riche moisson de «valeurs » et de «traits» populaires qu'engrange la description ethnographique de Hoggart s'est effectuée par une prospection du monde local ou familial de «l'entre-soi » populaire. Que ces expressions de la culture populaire " au repos " et «à distance » ne représentent pas un danger politique ou idéologique pour les classes dominantes est une autre histoire, qui ne saurait se substituer à la tâche de description qui incombe à la sociologie (et d'ailleurs bien des attitudes les plus "armées» de la culture militante peuvent se révéler à l'analyse historique aussi inoffensives pour les dominants). En tout cas le sociologue se laisserait encore entrainer par les prestiges de l'homologie entre rapports de sens et rapports de force s'il voulait à tout prix que là ou le rapport de force se noue en affrontement et, le cas échéant, se transforme ou s'inverse historiquement, là aussi la culture dominée s'émancipe le plus complètement de l'influence et de l'obsession de la culture dominante: on a plutôt vu le contraire dans l'histoire culturelle des révolutions ou des post-révolutions. L'aptitude à l'altérité culturelle des plus faibles n'est pas nécessairement la plus productive symboliquement là où les plus faibles sont au plus près des plus forts parce qu'ils les affrontent et s'y mesurent. C'est l'ambiguïté 
fondamentale introduite par un concept comme celui de «culture de résistance » que de convier, en se référant à la fois et indistinctement aux rapports de force entre groupes et aux rapports de sens entre cultures, à voir dans la situation d'affrontement inégal le principe fécond de toutes les productions populaires.

C. GRIGNON.- J'aimerais revenir, parce que je les trouve exemplaires, sur les réserves que suscite «l'authenticité » de l'expérience que décrit le texte de Navel. Il ne vient à l'esprit de personne de suspecter le sérieux scientifique du choix méthodologique de Labov quand il met cul par-dessus tête les choses de la linguistique, décrivant, par une inversion complète du centre et des marges, le langage semi-chàtié des "paumés » comme une maîtrise incomplète du système dialectal du VNA dont les règles sont définies par la pratique des "gars dans le coup ", marginaux absolus. Et voilà que Navel qui écrit par rapport à sa biographie sociale, sur son milieu et sa culture d'origine est immédiatement suspecté, lui, lorsqu'il réalise une opération logiquement équivalente à celle de Labov, de piéger le lecteur et de produire un témoignage biaisé, inutilisable pour l'analyse sociologique. On doit s'interroger sur la dissymétrie du traitement infligé au linguiste et à l'écrivain. Sous ce rapport, à savoir l'effet de rupture et de décentrement par rapport à l'accommodation réglée d'avance sur les rapports symboliques entre les groupes, on ne voit pas pourquoi, puisqu'elles nous rendent des services équivalents, l'abstraction scientifique, qui est pourtant elle aussi construite d'un point de vue qui n'est en aucun cas l'expression directe de l'expérience indigène, bénéficie d'un préjugé favorable que la fiction littéraire se voit en l'occurrence refuser. Est-ce seulement la méfiance à l'égard des techniques d'interprétation soustraites à la vérification empirique qui me retient de dire que le nom même de Navel, en tant qu'il désigne un romancier populaire, a de bonnes chances d'être associé dans le "sentiment linguistique »-il faudrait dire phonologique du public cultivé, à " naïf » et à « nave », alors que celui de Ravel, en tant qu'il désigne un musicien savant, ne peut au grand jamais être associé à « rave »?

J.-C. PASSERON.- En effet, ce n'est peut-être pas seulement à la science et à la littérature que s'applique la différence de traitement qui surgit spontanément dans les réactions de l'auditoire, voire dans nos propres attitudes quand nous ne les analysons pas. La tentation de recourir à « deux poids deux mesures » pourrait bien s'alimenter aussi à la difficulté de soupeser équitablement le savant populiste et l'autodidacte, l'intellectuel centrifuge et l'intellectuel centripète, même quand il nous convient à la même gymnastique. Qui peut être sûr qu'il échappe complètement à la certitude intuitive qu'il y a toujours du mérite à "descendre " alors qu'à "monter» on mérite d'abord le soupçon éthique? Axiome paradoxal de mécanique sociale qui commande pourtant bien des évaluations, y compris dans la mauvaise conscience des individus en voie d'ascension, alors qu'on n'y voit pas d'autres justifications que le privilège supplémentaire qu'il procure aux titulaires des positions élevées « condamnés » à mériter quoi qu'ils fassent.

R.-M. LAGRAVE.-Je ne suis pas tout à fait d'accord; effectivement, il ne faut pas soupçonner G. Navel de je ne sais quoi, mais il faut le replacer à l'intérieur d'un ensemble sociologique défini.

C. GRIGNON.- C'est plus facile à dire qu'à faire. Sans nous lancer dans la sociologie de la littérature, on peut toujours essayer de reconnaître les limites que les conditions sociales dans lesquelles il a été produit imposent à l'utilisation sociologique d'un texte comme celui-ci. Disons pour commencer qu'il n'est pas facile de distinguer, dans les réactions que le texte de G. Navel a suscité, entre l'inquiétude professionnelle légitime, qui incline à y voir quelque chose de trop écrit, de trop « littéraire », et la méfiance que suscite, auprès 
des intellectuels, tout écrivain d'origine et d'inspiration populaires dès lors qu'il a si peu que ce soit « réussi » (cf. les cas extrêmes de Guéhenno, raillé par Sartre du haut de l'École normale, ou de Giono, vilipendé en fin de carrière par la gauche bien pensante). Dire qu'il ne peut y avoir de véritable écrivain populaire, que tout écrivain cesse d'être authentiquement populaire dès lors qu'il parvient à être un authentique écrivain pourrait bien être encore une manière détournée de reconnaître qu'il ne peut y avoir d'écrivain que bourgeois : le sociologue doit au moins se demander au nom de quoi il conviendrait de réserver "l'écriture » et ses complications à l'expression du mode de vie et des goûts de la classe dominante et la sincérité naïve et désarmée à la description de la vie des " simples ", pourquoi ce qui est considéré comme de l'Art - et du grand ! - chez Proust deviendrait de l'artifice chez Navel ou chez Poulaille. S'il est vrai que l'expression littéraire de l'expérience que les dominés ont de la domination est inévitablement ambiguë, dans la mesure où ceux qui entendent conserver ou adopter le point de vue des dominés utilisent un instrument qui appartient à la culture des dominants, ce n'est pas pour autant qu'il faut mettre sur le même plan et récuser en bloc tous les " témoignages " littéraires. Quel que soit l'effet de domination et de retraduction exercé par «l'écriture ", la manière dont on s'en sert pour décrire les rapports entre les classes et entre les cultures diffère selon qu'on est, au départ, un indigène de la culture savante ou un indigène de la culture populaire, selon qu'on est devenu écrivain en se prolétarisant ou en s'embourgeoisant, selon qu'on a dû apprendre à écrire ou apprendre à travailler, etc.

De ce point de vue, les tentatives pour constituer une littérature savante d'inspiration populaire - entendons par là une littérature qui se donne pour thème central la vie et les mœurs des gens du Peuple - renvoient à deux courants sociaux de provenance et de direction opposées. Pour l'essentiel, cette littérature va au Peuple. Issu du naturalisme de Zola, bénéficiant de l'aura d'ancêtres comme George Sand ou Hugo et de la protection des grands écrivains humanistes, comme Anatole France, Romain Rolland et Henri Barbusse, le courant populiste, qui se constitue en école vers 1930 (avec notamment la fondation d'un prix littéraire) et dont les chefs de file sont des romanciers professionnels comme Léon Lemonnier et André Thérive, s'appuie sur une tradition proprement littéraire et constitue à tous égards le courant dominant, le plus reconnu, le plus « légitime», de la littérature d'inspiration populaire ${ }^{2}$ : l'école populiste parvient à attirer, notamment par l'intermédiaire du prix qu'elle décerne, des indigènes de la culture populaire, comme Louis Guilloux ou Bernard Clavel, et même à annexer, pour la "postérité ", dans des Dictionnaires de littérature, qui n'y regardent pas de si près, des adversaires déclarés comme Henri Poulaille, le fondateur de l'« école prolétarienne ». La forme achevée du populisme est réalisée par les clercs-ouvriers, prêtres ou professeurs, qui choisissent, quelques années plus tard, de rompre sans retour (du moins en principe) avec leur milieu d'origine, d' " aller au Peuple » de manière " concrète » en vivant la " condition ouvrière " et qui renvoient vers le public cultivé un témoignage à la fois lisible et authentique, ou du moins " authentifié » par le sacrifice de leur carrière à leur engagement; c'est le cas bien connu de Simone Weil, professeur au lycée du Puy puis ouvrière chez Renault, de Michèle Aumont, professeur de philosophie, "embauchée volontaire» en usine à la veille de passer l'agrégation, de Jacques Valdour, professeur lui aussi, mais maurassien ; c'est le cas aussi des «établis»-parfois le temps d'un rétablissement au CNRS ou dans une université - d'après 1968.

Ce n'est pas parce qu'elles revêtent une forme littéraire que les représentations de la culture populaire qui sont obtenues au prix de cette plongée, fictive ou réelle, dans la 
condition ouvrière, diffèrent des représentations, spontanées ou élaborées, naïves ou savantes, que s'en font les indigènes de cette culture ; l'exemple-limite des clercs-ouvriers rappelle qu'il ne suffit pas de changer de classe et de descendre, même pour de bon, les degrés de l'échelle sociale pour oublier sa culture d'origine, pour intérioriser la culture de sa classe d'élection et pour prendre sur la relation de domination entre les cultures le point de vue de la culture dominée - pas plus qu'il ne suffit de s'expatrier pour se déculturer et se ré-acculturer. Si les transfuges en provenance de la classe dominante sont toujours perçus, quelques efforts qu'ils fassent pour apprendre la langue, corriger leurs manières, bref pour "s'assimiler ", et quelque sympathie que suscitent ces efforts, comme des étrangers par les membres de leur classe d'adoption, c'est sans doute, outre qu'il leur manque de n'avoir pas eu à choisir et qu'ils finissent toujours par repartir vers leur classe d'origine (ne serait-ce que sous la forme d'un livre posthume), qu'ils continuent, quoi qu'ils fassent, à déchiffrer la condition populaire par l'intermédiaire du « code » de leur culture d'origine. Ainsi, comme le note M. Ragon, S. Weil ne voit pas les "petites" joies, pour elle "insignifiantes", qui éclairent la vie d'une ouvrière " ordinaire ", robe neuve, paye du samedi, bal du dimanche, etc.; « journal d'usine », le journal qu'elle tient est encore une manière de journal intime, comme ceux que tiennent à la même époque A. Gide ou J. Green. De ce point de vue, le déclassement volontaire des clercs-ouvriers apporte une nouvelle illustration à la question des relations entre rapports de force et rapports de sens. Si le fait de partager la condition populaire les range sans équivoque du côté des dominés dans la lutte entre les classes, ils demeurent à leur insu dans l'autre camp pour tout ce qui concerne la lutte entre les cultures ; l'histoire des relations entre les militants ouvriers et les intellectuels originaires des classes moyennes et dominantes fournit quantité d'exemples des malentendus que suscite ce porte-à-faux chaque fois que la dimension symbolique des luttes politiques ou syndicales prend de l'importance.

G. Navel fait partie du courant inverse, qui part des classes et de la culture dominées pour aller vers la production littéraire, et qu'illustrent les trajectoires de J.-J. Rousseau, de Péguy, de Gorki ou de Jack London. Ce n'est pas seulement parce qu'ils se nourrissent de l'expérience vécue et d'une familiarité plus grande avec la culture des classes dominées que les textes produits dans le prolongement de ces trajectoires peuvent avec des risques moindres servir de support à une analyse secondaire, mais parce que les conditions de vie et de travail des classes populaires ont, cette fois, quelques chances d'être appréhendées et décrites du point de vue de la culture qui leur correspond. Mais on ne peut transformer le soupçon diffus d'«embourgeoisement» et d'«inauthenticité » qui pèse automatiquement sur les écrivains d'origine populaire en connaissance utile des biais qui, même dans ce cas, le moins défavorable, interdisent de traiter un texte comme un comportement culturel observé selon les régies de la méthode ethnographique que si, considérant chaque texte comme un moment d'une trajectoire sociale, on prend en compte, autant que faire se peut, l'ensemble des facteurs qui déterminent la modalité particulière du rapport ambivalent que chaque écrivain d'origine et d'inspiration populaires entretient avec sa culture d'origine et, par l'intermédiaire de la littérature et de la culture savante, avec la culture dominante. Le degré et la manière dont un auteur s'écarte de sa culture de départ et de son expérience personnelle de dominé, dont il la retraduit et la «trahit » en la constituant comme objet de littérature, dont il la relativise et prend sur elle le point de vue de l'écrivain qu'il travaille à devenir, dont il la retourne contre les contraintes et les humiliations que lui inflige le milieu littéraire, dont il importe dans l'exercice du métier d'écrivain les dispositions, les exigences et le «style» 
attachés à son milieu d'origine (par exemple l'amour du travail bien fait et l'horreur du " chiqué ») etc. varient selon qu'il s'agit d'autodidactes, comme H. Poulaille, E. Dabit ou G. Navel ou de boursiers comme L. Guilloux ou J. Guéhenno. Il faudrait aussi distinguer, ce qui est plus difficile, entre les anciens ouvriers devenus écrivains professionnels, comme H. Poulaille, et les semi-professionnels qui continuent ou qui se remettent à exercer, plus ou moins régulièrement, un métier manuel, comme G. Navel. Parmi ceux-ci il faudrait mettre à part le cas des paysans-écrivains, sans doute moins improbable et moins exceptionnel que celui des ouvriers-écrivains, et pas seulement à cause d'une incompatibilité matérielle moins grande entre le métier et la littérature: l'image sociale du paysanécrivain, qui a pour lui la tradition de la poésie et du roman bucoliques, le soutien du folklore et du régionalisme, la sympathie agissante de l'école primaire est beaucoup moins insolite et incongrue que celle de l'ouvrier-écrivain, qui a contre lui, en plus du mépris de classe et de l'inquiétude qu'il suscite sur le terrain politique, l'antagonisme entre l'Art et la Technique, l'hostilité à l'égard du " Progrès ", du « matérialisme » et de l'hybris de la science faustienne qui, de T. Gautier à F. Brunetière en passant par Baudelaire, Leconte de Lisle, Flaubert, Villiers de l'Isle-Adam, etc. constituent une tendance essentielle de la tradition littéraire française ; témoin, entre autres, la manière dont Flaubert se moque des poètes-ouvriers quarante-huitards dans L'éducation sentimentale. Et il faudrait encore analyser les relations entre trajectoires littéraires et trajectoires militantes, dont Émile Guillaumin, un des plus connus parmi les paysansécrivains, fournit une bonne illustration.

39 P. COHEN-SCALI.- Pour en revenir au texte de Navel, il me semble voir dans la première partie une sorte d'humour, de prise de distance qu'on peut considérer comme une forme de résistance qui s'exprimerait aussi dans la ré-interprétation par les classes dominées du rapport de domination qu'elles subissent. C'est bien ce que fait voir A. Cottereau dans sa préface au Sublime de Denis Poulot. Il montre que la dérision peut être une forme forte de la résistance populaire sur le terrain des luttes symboliques: témoin, par exemple, la manière dont certains ouvriers («les sublimes ») des années 1860-1870 retournaient au profit de contre-valeurs une chanson édifiante sur les «bons travailleurs » pour en faire un hymne à la paresse, ou érigeaient en système de vie valorisé (lui-même hiérarchise selon les degrés d'excellence dans la dissidence) absentéisme, "coulage ", sabotage ou alcoolisme. Ce détournement des conditions de vie imposées par le travail salarié implique bien un renversement total des valeurs imposées par les classes dominantes.

40 J.-C. PASSERON.- Mais quelles conclusions tirez-vous de ces phénomènes, effectivement fréquents, d'inversion culturelle plus souvent cantonnés, d'ailleurs, dans une fonction de fronde symbolique que de levier de la révolte? Sont-ils pour vous au centre ou à la périphérie de ce qui constitue les cultures populaires comme styles de vie?

41 P. COHEN-SCALI.- Ça montre au moins que l'intériorisation des valeurs dominantes ne va pas de soi, n'est pas la règle.

42 J.-C. PASSERon.- Certes. Mais qui prétend le contraire? Il est vrai qu'une application aveugle de la théorie de l'ordre légitime pourrait mener, dans un élan d'allégresse masochiste ou de déploration misérabiliste, jusqu'à cette extrémité : je l'ai constaté dans certaines thèses de troisième cycle. Ramener tous les effets de la domination symbolique à la pure et simple intériorisation par les membres des classes populaires de leur propre illégitimité culturelle interdit évidemment de décrire la gamme diversifiée des effets culturels que produit l'imposition d'un ordre légitime. Ce cas de figure existe pourtant, ne l'oublions pas; peut être jamais en toute pureté, au moins comme composante d'une 
ambivalence ou d'une alternance. C'est celui que Renan décrivait, idéal-typiquement, pour le vilain d'Ancien Régime, acceptant de vivre par procuration et délégation sa dignité sociale dans la puissance et les plaisirs du maître. Un tel rapport à l'ordre social, sinon heureux du moins indifférent ou résigné, pourrait bien d'ailleurs constituer un effet de l'intériorisation de l'ordre légitime aussi fréquent que celui, plus souvent décrit, qui s'exprime dans la conscience malheureuse ou torturée de l'indignité culturelle et qui se rencontre eh tout cas plus souvent dans les classes intermédiaires que dans les classes populaires. En tout état de cause, les signes extérieurs de la prosternation mentale, si spectaculaires chez les groupes dominés des sociétés paysannes de tradition clientélique ou patriarcale suffisent à montrer que le sociologue ne devrait jamais prendre au mot, chez les dominés, les manifestations trop affichées de l'abdication culturelle : elles ne trompaient pas aussi complètement les maîtres qu'elles ont pu tromper et fasciner le romancier narodnik. La réitération et la surenchère dans la soumission et l'approbation de l'ordre par les dominés est en effet toujours complexe : répéter et pratiquer - comme la vieille émigrée du Mezzogiorno dans l'autobiographie de Nucera - l'adage de journalier agricole "I padroni hanno sempre ragione» ne va pas sans calcul ni cautèle: c'est un condensé d'expérience historique de classe prolétaire qui ramasse dans un assez ostentatoire présent de l'indicatif bien trop de modalités verbales pour ne pas être suspect de dérober plus qu'il ne livre: il faut au locuteur populaire télescoper au moins l'indicatif de la loi naturelle et l'impératif de la maxime, le conditionnel du conseil de prudence et le déploratif ramassé en litote gnomique, le constat de perduration d'un passé composé de mémoire perdue et la prophétie qui, tout compte fait, se vérifiera au futur antérieur, pour se hasarder à dire sans risques le résultat d'un aussi millénaire calcul stratégique de minimisation du risque.

43 Mais il ne suffit pas de décrire les résistances que rencontre l'imposition des valeurs dominantes et de constater que les attitudes populaires ne se réduisent presque jamais à l'acceptation passive. L'inversion culturelle est encore un processus qui s'affronte de trop près à l'action de domination symbolique pour rendre compte de tout ce par quoi une culture populaire échappe à l'imposition de la légitimité culturelle. Ne cherchons pas à tous coups dans les formes d'expression réactives engendrées par la dénégation du dominant - puisque leur contenu culturel est mécaniquement commandé par le projet d'un refus idéologique de la domination symbolique et qu'en conséquence elles y réfèrent directement leur sens - le paradigme des capacités populaires à l'autonomie symbolique. Lorsque le concept de « résistance culturelle » en vient à recouvrir toutes les démarches populaires qui ne se réduisent pas à la soumission, il devient mutilation et souvent censure de la description. Il fait en tout cas contresens théorique lorsqu'il engage à trouver dans l'inversion le nerf de toute création populaire, dans la dénégation la forme de toute altérité. Les cultures populaires ne sont évidemment pas figées dans un garde-àvous perpétuel devant la légitimité culturelle, ce n'est pas une raison pour les supposer mobilisées jour et nuit dans un garde-à-vous constestataire. Elles fonctionnent aussi au repos.

L'exemple du "sublimisme" s'inscrit effectivement dans une série, fort riche historiquement et sociologiquement, de réactions idéologiques, par lesquelles des groupes dominés ont - à défaut d'autres armes culturelles et en l'absence de toute possibilité de révolte réelle - réussi à faire de la domination subie un objet symbolique à la fois distancé et apprivoisé par la dérision, l'humour agressif, la jactance revancharde ou, aussi bien, l'idéalisation éthique ou sentimentale de leur position: refrains de 
bagnards ou de galériens, chants d'esclaves, chansons de toile, rengaines militaires de «durs » des Bat' d'Af, complaintes évoquant les hauts faits des hors-la-loi justiciers, goualantes larmoyantes du malheur des pauvres, etc. C'est là assurément un principe productif du symbolisme dominé ; ce n'est pas le seul. Il faut se défier du plaisir ambigu qu'il procure à l'intellectuel - qui, comme on sait, sommeille en tout sociologue - toujours heureux de trouver dans ces militantismes symboliques (proches parents du militantisme qu'il préfère) l'essence de la culture populaire, la fine pointe de son autonomie. Tout au contraire, on est là au plus près d'un mécanisme de production symbolique particulièrement révélateur de l'hétéronomie des cultures dominées, parce que sa spécificité suppose justement qu'il fonctionne sous l'action directe du rapport de domination en sa forme la plus exigeante et la plus nue. C'est dans les groupes les plus " enchaînés ", les plus "enfermés ", ou les plus "écrasés ", dans les classes qui sont les plus continûment rappelées à une obéissance sans échappatoire ou à un sort subi sans espoir d'éclaircie que ce mécanisme est le plus productif puisqu'il constitue en ce cas le seul moyen disponible de faire symboliquement du rapport de domination autre chose que l'acceptation servile de ses effets. Loin qu'on y saisisse ce qu'une culture dominée peut produire de plus distinct, de plus distant par rapport aux effets de la domination, on y touche du doigt l'action directe de la servitude : c'est du B' à l'état presque pur (cf. schéma 2, p. 15).

Du même coup, il ne serait pas difficile de montrer que cette liberté minimale et résiduelle - celle de faire une nique symbolique à la domination en la chansonnant ou de " faire avec» elle en la mettant en musique- est une des réponses symboliques des dominés dont s'accommodent le mieux les dominants. Avant même que d'en faire leurs délices culturelles en les consommant, lorsque l'histoire les leurs a rendus digestibles en les aseptisant comme produits épurés de l'odeur de leurs producteurs et de leurs conditions de production, sous forme de kitsch, de folk ou de rétro (cf. tangos, canzonetta, flamenco, complaintes ou negro spirituals), les membres des classes dominantes les avaient toujours traités avec cette indulgence que les proviseurs réservaient aussi aux chahuts traditionnels; en tout cas les gardiens de l'ordre directement préposés à la tâche de son maintien (gardes-chiourme, contremaîtres, sous-offs) avaient depuis longtemps fonctionnellement apprécié la plupart de ces lamentations cadencées ou de ces imprécations réglées comme les meilleurs facilitateurs de l'exercice du commandement: les complaintes de servitude soutiennent le travail de la plantation ou du tissage, les chansons de galériens rythment efficacement le maniement de la rame; les gradés des régiments disciplinaires font volontiers répéter - peu importe les paroles - les chansons râleuses qui font marcher les fortes têtes au pas ou casser aux « Joyeux » des cailloux sous le soleil de Biribi. Ce n'est pas là "récupération», au sens où l'emploi de ce concept autorise aujourd'hui le discours automatique à voir, avant même d'y avoir regardé, dans le tissu de tout phénomène social la répétition monotone du même nœud éthique - celui qui condamnerait toute bonne volonté originaire, créatrice ou révolutionnaire, à se faire immanquablement piéger et digérer par une méchante stratégie d'universelle aragne. C'est tout simplement l'effet le plus immédiat de la dénégation du rapport de domination lorsque la révolte est mise à la portion congrue par la contrainte même qu'il exerce. La description sociologique ne peut éluder les fonctions intégratrices qu'assument ipso facto les produits d'une culture de résistance dont les pratiquants doivent agir sous le contrôle direct du rapport de domination: fonction technique par la scansion des tâches de servitude; fonction idéologique de revigoration du moral des dominés par l'obtention compensatoire de petites «victoires morales» du type de celles dont se revanchait le 
coolie Ah $\mathrm{Q}$ après chacune de ses humiliations et que condense le refrain de forçat qui aide à marcher enchaîné en conspuant le boulet : « la chaîne, c'est la géhenne ; mais c'est égal, ça n'fait pas d'mal ».

Entendons-nous bien : il advient des choses essentielles à une culture populaire du fait qu'elle est contrainte à fonctionner comme une culture dominée, c'est-à-dire inextricablement cornue culture d'acceptation et culture de dénégation, sub-culture et contre-culture. À la sociologie de ne pas les manquer: c'est analyse idéologique (interprétation de ses productions symboliques selon B'). Mais le sociologue manquerait autre chose de la culture populaire s'il était incapable de faire l'hypothèse interprétative qu'une culture populaire est aussi capable de productivité symbolique lorsqu'elle oublie la domination des "autres ", à tout le moins qu'elle parvient à organiser en cohérence symbolique dont le principe lui est propre les expériences de sa condition, y compris en ce qu'elle a de dominé : c'est analyse culturelle (interprétation du sens de ses productions symboliques selon B). Rien dans la théorie du symbolisme social n'interdit l'hypothèse que l'inconscience des relations sociales soit aussi productrice de sens que la conscience ; faute de quoi il faudrait supposer que le symbolisme social ne s'engendre que par la pensée adéquate des structures sociales, que toute pensée sociale n'en contient qu'autant qu'elle se rapproche de la sociologie : c'est bien ce à quoi tend, à la limite, le sociologue intellectuel ou l'intellectuel militant lorsqu'ils tendent à ne reconnaître un sens à des pratiques ou à des idées populaires que pour autant qu'elles s'orientent ou se refusent explicitement aux réalités et aux valeurs dont ils parlent. Comme souvent, c'est beaucoup prêter pour mieux soustraire; doter généreusement en un sens que l'on contrôle parce qu'on le dit, pour mieux refuser tout droit à un autre sens. Il y a bien quelque chose de cette avarice symbolique dans la réticence du sociologue à reconnaître que la culture populaire puisse encore travailler symboliquement quand elle est de campos, i. e. quand elle travaille sur d'autres problèmes que ceux que la domination subie "devrait» lui poser. L'intellectuel trouve que la culture populaire lui fait faux bond lorsqu'il ne peut plus être sûr qu'elle «ne pense qu'à ça ».

L'analyse des traits culturels réactifs appartient assurément à la prospection du contenu et de la logique de la symbolisation effectuée en situation dominée. Mais cette analyse ne doit jamais interdire, au nom de l'usage exclusivement vertical du schéma marxiste (de la lecture des rapports de sens par référence à la seule réalité des rapports de force) la description des actes et des formes de symbolisation populaire par référence à une condition qui s'ignore ou joue à s'ignorer comme condition dominée. La conscience du rapport de domination, en tout cas la conscience de son arbitraire (surtout au sens saussurien) n'est pas aussi obsessionnellement présente dans la pensée populaire que dans la réflexion ou la mauvaise conscience des intellectuels inévitablement portés à ne voir, dans les pratiques populaires réussissant à oublier qu'elles sont dominées, qu' " aliénation » (ou consentement à un sens imposé). Il n'existe aucune raison suffisante de faire fonctionner à sens unique la trop célèbre distinction hégéliano-marxiste de la "classe en-soi » et de la "classe pour-soi » afin de réserver le surcroît exclusif de conscience que nomme le " pour-soi » à ce supplément d'âme symbolique qu'apporterait aux dominés la conscience de la domination et de la nécessité de la lutte ; il est difficile de refuser la conscience pour soi à une conscience qui pense et agit pour son propre compte, du seul fait que cette conscience ne conduit pas directement au sens de l'histoire ou de la machinerie sociale. La description sociologique trouve aussi son compte à mettre parfois l'en-soi du côté de la structure. L'oubli de la domination symbolique n'est évidemment 
pas rupture ou émancipation des conditionnements qui déterminent une condition dominée, mais il autorise des actes de symbolisation dont le sens se réfère seulement aux caractéristiques concrètes de la condition, sans les sur-déterminer par le sens que cette condition tient du fait d'être celle des groupes dominés. Je ne sais si les idées des groupes dominants peuvent être de fond en comble interprétées en tant qu'«idées de leur domination » ainsi que le dit Marx; on comprend en tout cas qu'il y ait toujours intérêt symbolique pour les dominants à penser et à juger à partir du principe qui fait leur "valeur » culturelle et sociale. Mais il n'en va pas de même (autre dissymétrie) pour les dominés qui n'ont pas un intérêt continu - en tout cas symbolique - à n'avoir que des idées qui seraient celles de la domination (qu'ils subissent).

D'où le problème particulier que pose à la description et à l'interprétation le sens des cultures populaires: manquer le sens que livre l'application d'une des deux grilles d'analyse n'est pas seulement sous-interprétation, mais dans le même mouvement, surinterprétation corrélative. C'est à la fois sur- et sous-interprétation que d'user exclusivement d'organisateurs de la description tels que les concepts de "récupération ", "contestation » ou "manipulation » qui reviennent au même lorsqu'ils font voir par exemple dans la promiscuité et l'insalubrité surpeuplée de la «tanière » ouvrière du XIX siècle la résistance, sinon la lutte de valeurs proprement populaires contre les tentatives de contrôle policier ou de domestication culturelle des classes «dangereuses » par les classes dominantes, leurs valeurs et leurs agents, ou, aussi bien, encore qu'en sens inverse, dans le rituel ou les fêtes d'une vie rurale ronronnant dans son quant-à-soi parcellaire et traditionnel, l'aménagement symbolique de la parfaite soumission des producteurs, l'opium du peuple paysan. Le culturalisme à œillères fait symétriquement injustice interprétative aux groupes dominés dont il décrit la " culture » insulaire comme s'il s'agissait d'îles du Pacifique, c'est-à-dire en oubliant des rapports de domination dont les effets n'oublient pas ceux qui les oublient. Mais trêve de caricatures: les deux systèmes d'analyse sont producteurs de sens. La difficulté propre d'une sociologie du symbolisme dominé, c'est que les traits et les comportements dominés ne sont jamais purement autonomes ou purement réactifs. Le concept d'ambivalence rappelle qu'il est rare qu'un trait culturel dise tout ce qu'il a à dire dans une des deux grilles conceptuelles de description. Le concept d'alternance rappelle qu'il peut devenir absurde, selon les cas (quel groupe social ? quel moment? quelle dimension de la pratique? quel espace de vie? ) de s'en tenir décisoirement à la grille qu'une affiliation d'école a fait choisir. Je ne veux donc surtout pas dire que la sociologie des cultures populaires soit plus productive ou théoriquement mieux ciblée quand elle s'inscrit dans une des deux hypothèses de description plutôt que dans l'autre. Il est de bon contrôle épistémologique de ne jamais oublier l'une au profit de l'autre, d'interroger la description produite par le langage de l'une par référence à la description que produirait le langage de l'autre.

C. GRIGNON.- Restera toujours qu'une des deux logiques, que vous semblez renvoyer dos à dos est plus imaginaire, mais peut-être moins arbitraire que l'autre. Il faut en effet distinguer entre la recherche de cas concrets d'inversion (dans laquelle la discussion a un moment risqué de s'enliser) et la variation imaginaire à laquelle se livre Labov, lorsque, changeant décisoirement de point de vue, il constitue le vernaculaire du prolétariat noir comme pôle de référence, reléguant du même coup le langage dominant au rang de dialecte. Que Labov croie ou non à la réalité sociale de cette inversion de la polarité n'a au fond guère d'importance; même s'il entend le saisir pratiquement, par le moyen de l'enquête empirique, le renversement qu'il opère n'a pas à être plus réaliste que la fiction 
construite par le romancier. Pour rendre compte de ce qu'il découvre en parcourant la relation de domination en sens inverse, le sociolinguiste n'a pas besoin que le vernaculaire du prolétariat noir soit pour de bon, potentiellement ou « dans une certaine mesure », la langue dominante ; il suffit de se donner les moyens et les outils nécessaires pour faire comme s'il en était ainsi. L'efficacité scientifique du procédé dépend du degré auquel les résultats qu'il permet d'obtenir peuvent encore faire l'objet d'une lecture consciente des réalités du contexte. De ce point de vue, il faut dire que Labov, qui met en relation le fonctionnement interne des groupes avec les pressions et l'attraction émanant des institutions "légitimes ", comme la famille ou l'école, n'est jamais complètement victime de la dérive vers l'autonomisation formelle. L'étude interne et «concrète » des parlers adolescents ne se réduit pas, chez lui, à une description ethnographique fermée ; elle se fait à l'occasion et par l'intermédiaire de situations de contact et de conflit entre des agents et des groupes plus ou moins scolarisés, plus ou moins intégrés dans une bande ou au contraire dans leur famille, bref, occupant des positions différentes par rapport aux pôles antagonistes de la langue et de la culture. En d'autres termes, Labov réussit à saisir des espèces particulières de cultures populaires (culture de la rue, cultures adolescentes, etc.) à la fois en elles-mêmes et dans la relation qu'elles entretiennent avec la culture non populaire, ou, pour reprendre les termes de Hoggart, par l'intermédiaire de la relation entre « Nous » et les « Autres ».

À la condition d'être utilisée de cette façon, non comme une description de la réalité sociale, mais comme un procédé métaphorique, l'inversion de la polarité symbolique a au moins l'avantage de faire apparaître l'ethnocentrisme tendanciel ou latent qu'enferme l'approche légitimiste des cultures populaires. En épinglant avec un sérieux scientifique imperturbable les tournures « correctes " (par rapport aux normes dominantes) comme autant de «fautes ", Labov rend sensible la violence que la description savante du parler populaire en termes d'écarts à la norme fait subir à celui-ci; là comme ailleurs, les dominants ne prennent conscience du racisme que lorsqu'il leur est renvoyé par les dominés. En traitant les bons élèves de « paumés ", il montre comment les mots-clés de la sociologie de la culture pourraient être retournés pour décrire la culture dominante. Prendre sur l'objet le point de vue des dominés, retraduire leur posture mentale en posture méthodologique, transformer en outils de recherche leurs armes habituelles - l'insolence, la gouaille, la provocation (cf. ce qu'on a dit à propos du texte de Navel) - est sans doute un des rares moyens de mettre en évidence ce qui manque à ceux qui ont tout, élèves des Grandes Écoles, Grandes Familles, Patronat, etc., de décrire pour une fois et à son tour l'excellence sociale par référence et par défaut, à la limite en termes de handicaps. Savant "populiste », mais populiste savant, qui, plus avisé que les clercsouvriers, a su emprunter aux ethnologues des techniques rationnelles de plongée, Labov fait entrevoir ce que pourrait être une sociologie de la culture faite par un indigène de la culture populaire acculturé à la culture savante ; il fait apparaitre la " tache aveugle » de la démarche légitimiste, qui doit sans doute une bonne part de sa clairvoyance désabusée à la familiarité complice que les sociologues entretiennent avec le goût et la culture dominants. Ainsi, le "procédé Labov» permet de se prémunir contre le risque d'absolutiser les hiérarchies culturelles que l'on travaille à objectiver, au risque évidemment de retomber dans les naïvetés du relativisme culturel. C'est un peu un succédané, pour le sociologue, du recul dont bénéficie automatiquement l'historien de la vie quotidienne, à qui le côté désuet et dépassé des pratiques qu'il étudie rappelle constamment l'arbitraire de tous les goûts, y compris du goût dominant. 
51 M. GRUMBACH.- Je voudrais revenir sur le rapport des classes dominantes à leur propre norme, à la norme légitime. C'est une question qui n'a pas été vraiment abordée ; on a beaucoup parlé des effets du légitimisme sur la description du rapport des classes dominées à la domination, mais on a négligé ce qui se passe à l'autre bout. La dérive légitimiste se traduit aussi par une idéalisation du rapport que les classes dominantes entretiennent avec les normes dominantes: on fait comme si l'identification des pratiques à la nonne légitime et, en ce qui concerne le langage, du vernaculaire des classes dominantes à la norme linguistique, allait de soi. C'est précisément cette identification que récuse Navel: dans le texte que vous avez cité, il ne fait rien d'autre que de mettre l'accent sur l'écart entre les pratiques réelles des dominants et leurs propres normes (cf. ce qu'il dit sur le « petit goret »). Labov, de son côté, rappelle que le vernaculaire des classes dominantes ne se confond en aucune manière avec la norme linguistique, qu'il ne constitue jamais qu'une "sorte d'oralisation de la langue écrite »; dans la plus grande maîtrise du langage, si souvent contestée, dont savent faire preuve à l'occasion les dominants, il voit en effet des situations sociales dans lesquelles sont produits les discours soumis à l'analyse savante, et notamment de la situation d'entretien; non seulement, il dit que ces artefacts ne représentent en aucun cas le vernaculaire des classes dominantes, mais il renverse complètement l'analyse habituelle, en affirmant que c'est dans les classes populaires et dans le style familier qu'il y a le plus de phrases grammaticales. À la limite, et pour caricaturer un peu, la dérive légitimiste pousse le sociologue à supposer que les classes dominantes qui visitent les musées sont d'emblée en possession de la lecture de Panofsky. À tout le moins, il faut signaler la dissymétrie des traitements respectifs dont sont l'objet les manquements à la norme selon qu'ils sont le fait des classes dominantes ou des classes dominées; dans le cas des dominés, l'écart est toujours sanctionné ; dans celui des dominants, il n'est ni sanctionné, ni mesuré, ni même perçu.

C. GRIGNON.- Effectivement, tout se passe comme si la perspective légitimiste incitait la sociologie de la culture à considérer que, du côté des classes dominées, le manquement à la norme est la régie, que les erreurs de déchiffrement, les fautes de goûts, les ratés, etc. sont, dans ce cas, des propriétés de la classe (et donc des propriétés sociologiques), le produit de handicaps collectifs, auxquels n'échappent que des individus exceptionnels ; et à l'inverse, que ces manquements, quand ils se produisent du côté des dominants, sont des accidents individuels, d'ordre moral ou psychologique, négligeables pour le sociologue. Mais il faut quand même rappeler que c'est en autonomisant dans un premier temps la culture des dominants par rapport à leurs comportements culturels réels, ou plus exactement en refusant de considérer ceux-ci autrement que comme des manifestations et des actualisations de la culture dominante que la sociologie de la culture peut briser le lien "naturel» que les indigènes de la culture dominante entretiennent avec celle-ci. C'est une abstraction de principe, analogue à celle du linguiste qui ne s'intéresse aux paroles que dans la mesure où elles renvoient à la langue, qui permet au sociologue de faire apparaître le sens de la relation entre les modèles culturels légitimes et les possessions des dominants, entre le droit et l'avoir, et de montrer que les normes de la culture, du goût ou du savoir-vivre ne sont jamais que l'expression, travaillée, travestie et institutionnalisée, d'intérêts et de dispositions qui ne sont jamais, eux-mêmes, que le produit et le reflet des propriétés de la classe dominante. La brutalité réductrice avec laquelle opère le sociologue est en fait un moyen subtil de prendre au mot et sur le fait la tautologie sur laquelle se fonde l'assurance de classe des 
dominants, à savoir qu'ils ont ce qu'il y a de mieux parce qu'ils sont les meilleurs et que ce qu'ils ont est ce qu'il y a de mieux parce qu'ils sont les meilleurs. Les critiques que les indigènes ou les familiers de la culture dominante ont beau jeu d'adresser au sociologue apparemment balourd se situent bien en deçà de cette rupture; en sacrifiant des individus à la classe, et en donnant l'illusion de sacrifier la classe elle-même à la norme, ils sauvent l'essentiel en mettant hors de portée et hors de cause ce qui légitime la domination; c'est là ce qui les pousse à faire appel au sens commun et à rappeler qu'en effet les entrepreneurs ne sont pas toujours entreprenants, les ingénieurs ingénieux, les savants savants, les nobles nobles, les femmes du monde bien élevées, etc.

Cela dit, ce parti risque fort de conduire le sociologue à sélectionner, parmi les comportements culturels réels des membres des classes dominantes ceux qui se rapprochent le plus de cette culture, qui en donnent l'idée la plus exacte (ou la plus conforme à la construction que le sociologue est en train d'élaborer), bref à privilégier les comportements d'excellence et à rejeter comme non significatifs ou au mieux secondaires les écarts à la norme, les ratés, les lapsus, etc., un peu à la manière d'un linguiste qui sélectionnerait les tournures les plus « correctes », les «meilleurs » accents, les discours sans faute, etc. C'est là, je crois, qu'il faut chercher l'origine de la dérive que vous signalez. La sociologie de la culture dominante s'expose du même coup, après être partie d'un si bon pas, comme disait Péguy, à contribuer à son tour et à sa manière à renforcer la croyance selon laquelle les dominants participent tous et toujours de l'excellence de leur culture, même s'ils se montrent constamment inférieurs à celle-ci. Elle établirait sans doute d'une manière plus irréversible le sens de la relation entre les modèles culturels légitimes et les possessions, matérielles et symboliques, que la classe dominante se réserve (ou dont elle tend à se réserver l'accès), si elle se retournait à temps vers la recherche systématique des écarts: a) entre les usages légitimes (les «déchiffrements adéquats ») qu'appellent les possessions des dominants et les usages réels que ceux-ci font de leurs possessions ; $b$ ) entre les modèles culturels légitimes et les goûts réels, tels qu'on peut les saisir à travers les consommations et les pratiques; $c$ ) entre les goûts proclamés par référence aux modèles et aux hiérarchies légitimes (qui ne coïncident pas nécessairement avec ceux-ci) et les pratiques réelles. Certaines descriptions, un peu trop édifiantes, du style de vie des dominants donnent évidemment envie d'introduire dans le discours sociologique les bibliothèques pleines de livres jamais ouverts, les musées traversés au pas de charge, les concerts suivis d'une oreille somnolente, les buffets pris d'assaut, etc. et de retourner vers l'étude du rapport que les dominants entretiennent avec leur culture l'arsenal des concepts malveillants ou condescendants, comme «bonne volonté culturelle", "simili», "erreur de déchiffrement", "allodoxia», etc. que la sociologie de la culture tend à réserver aux petits-bourgeois, aux autodidactes, aux «demi-habiles». Plus sérieusement, on peut espérer que l'analyse systématique des manquements des dominants à la norme légitime permettrait de progresser dans l'étude de la transmission de l'héritage culturel (en montrant comment les héritiers, pas forcément à la hauteur de l'héritage, le gèrent, le dilapident, le transforment) et dans celle des relations entre l'offre et la demande des différentes espèces de biens culturels (ou si l'on veut entre le « champ » de production et le «marché »).

Reste qu'on court le risque de trouver le "bon " goût d'autant meilleur qu'on se sera donné les moyens de montrer combien celui des dominants est détestable, la " haute " culture d'autant plus haute qu'on aura fait voir à quel point celle des gens cultivés est 
médiocre, bref, qu'on s'expose ainsi à conférer indirectement un supplément inattendu de légitimité à la culture légitime.

J.-C. PASSERON.- La teneur quelque peu abstraite ou polémique de notre débat ne doit pas donner à croire qu'il n'engagerait que les choix ultimes de la formulation conceptuelle des descriptions ou les humeurs spontanées du descripteur par les valeurs connotatives des mots employés. Ce sont les actes les plus concrets du travail sociologique, les choix du protocole de recherche ou des techniques d'observation et de mesure qui sont en jeu. Pour seul exemple de la portée méthodologique des risques croisés d'artifice et de régression ethnocentrique inhérents à la problématique du relativisme culturel et à celle du légitimisme spontané, je prendrai l'enquête de Schatzman et Strauss que nous avions fait figurer dans le Métier de sociologue ${ }^{3}$ et qui porte sur la variation sociale des formes de narration entre les middle-classes et les working classes. Le chapeau qui précède ce texte était lui-même quelque peu ambigu: cette recherche était en effet bienvenue pour illustrer les différences entre les formes d'organisation verbales et le rapport au langage propres aux différentes classes sociales, et dont la plupart dos instruments traditionnels du questionnement sociologique, et nommément l'entretien, ne tiennent guère compte en supposant implicitement la neutralité sociale du langage et des situations de langage livrant l'information traitée : « l'entretien le plus simple fait intervenir des techniques de communication et des formes d'organisation de l'expérience qui opposent point par point classes moyennes et classes populaires ${ }^{4} »$. Mais les auteurs du chapeau laissaient percer quelque hésitation sur la manière dont étaient décrites ces différences (en termes de "plus» ou de "moins», de maitrise inégale) puisqu'ils concluaient seulement et prudemment que : «tirer toutes les conséquences de ces analyses obligerait à renoncer à l'illusion de la neutralité des techniques - en l'occurrence celle de l'entretien et du terrain choisi pour l'entretien - et à se donner les moyens de contrôler, pour en tenir compte, les effets de la situation d'entretien ».

Les hypothèses de Schatzman et Strauss découlent en effet de ce qu'a de scientifiquement productif la problématique relativiste, à savoir l'incitation à décrire "sans préjugés » les formes d'organisation du récit pour essayer de montrer comparativement qu'elles ne sont pas les mêmes dans les classes populaires et dans les classes moyennes: les formes populaires pourraient être autre chose que des formes faibles ou exténuées du seul récit possible, celui que l'on centre spontanément sur le récit littéraire parce que les classes dominantes y reconnaissent l'élaboration de leur manière de raconter. C'est donc la structure narrative des comportements verbaux qui est ici l'objet d'une enquête menée par l'analyse d'entretiens avec les habitants d'un village de l'Arkansas après une tornade. Les deux groupes de l'échantillon (définis à la fois par des critères de revenu et de niveau d'instruction) se trouvent socialement éloignés et même polairement opposés dans la stratification de la société américaine. Les conclusions de Schatzman et Strauss - étant donné la méthode de traitement appliquée au corpus - sont indiscutables tant qu'elles énoncent le constat de la variation sociale, dans sa généralité et sur la tâche discursive qui définissait l'enquête :

«Les différences constatées entre la classe populaire et la classe moyenne sont frappantes, et, une fois formulé le principe de cette différence, il est surprenant de voir avec quelle facilité on peut détecter la structure de communication caractéristique d'un groupe, à la seule lecture de quelques paragraphes d'un entretien ${ }^{5}$."

57 Mais on va voir immédiatement que, dès qu'il s'agit de décrire ce que décrit cette mesure, les dérapages de l'inférence sont gouvernés par le langage de la description c'est-à-dire 
par la théorie inhérente à tout langage, et que la théorie de l'inégalité des compétences formelles selon les classes revient au galop, y compris dans une problématique relativiste. Ne retenons, en les résumant, que deux conclusions de Schatzman et Strauss :

1. Les locuteurs de classe populaire inscrivent leur récit " dans une seule perspective »: ils décrivent ce qu'ils ont observé du lieu où ils étaient placés et du seul point de vue de leur expérience affective ou participative; alors que les autres locuteurs changent de point de vue dans leur narration, se plaçant successivement du point de vue de la CroixRouge, d'autres institutions, des victimes, des ambulanciers, des gens qui regardaient de leur fenêtre, etc. C'est sans doute exact, mais est-ce dire exactement ce constat que de le conceptualiser dans une inaptitude à se décentrer qui serait propre aux démarches logiques des classes populaires? L'expression apparait pourtant comme allant de soi dans le commentaire. On voit que la régression légitimiste vers l'ethnocentrisme, qui consiste ici à doter immédiatement du signe "plus » et du signe "moins" les deux pôles d'une différence (opération qui sitôt inscrite dans le langage scientifique bénéficie de l'évidence spontanée qui l'y a fait inscrire) n'est pas bannie d'un coup de baguette magique, par le choix relativiste de décrire la variété et la variation sans préjuger au départ de l'infériorité ou de la supériorité. La dérive descriptive est en effet d'autant plus frappante ici que le protocole de recherche était conçu explicitement pour déjouer le piège ethnocentrique premier : les sociologues n'ont évidemment pas cédé à la naïveté qui eût consisté à comparer les deux classes sociales par des indicateurs donnant mécaniquement l'avantage à la middle-class (richesse lexicologique, densité des conjonctions de subordination, légitimité culturelle $d u$ " registre » stylistique ${ }^{6}$ ) ; ils ont pour ne pas être victimes de la trop évidente hiérarchisation sociale de ces "marqueurs" négligé les formes de la grammaticalité « de surface» des deux discours pour centrer l'analyse sur des formes "profondes", indépendamment de leur réalisation linguistique: les structures narratives qui sont, comme les structures argumentatives, des structures logiques apparemment capables de se prêter à une comparaison de "compétence " puisque le degré de complexité qu'elles révèlent dans des utilisations effectives semble bien autoriser des constats d'inégalité dans la maitrise logique des opérations. Mais c'est un piège second qui attend ici le sociologue : la compétence logique n'est pas liée à son actualisation comme le sont compétence et performances linguistiques. Faute d'interroger sociologiquement les rapports entre classe sociale et terrain d'actualisation de la performance (ici la demande de narration en situation d'entretien) la certitude d'avoir déjoué le piège premier engage plus profondément dans le second.

2. La manière dont Schatzman et Strauss utilisent le traitement des classifications le montre encore mieux :

«Les informateurs de classe populaire classifient peu. Ils se réfèrent généralement à des individus particuliers qu'ils désignent souvent par un nom propre ou un nom de famille; cette manière de procéder n'éclaire la description et ne facilite l'identification des personnes mises en cause que lorsque l'informateur se contente de rapporter les expériences de quelques individus bien définis ${ }^{7}$. »

Plus généralement, nous dit-on, on constate une pauvreté des procédés classificatoires, un faible degré de généralité de la taxinomie - qui s'exprime par exemple dans l'incapacité à identifier des institutions comme la Croix-Rouge - ou, à la limite par l'ultragénéralité d'une classification unique qui n'oppose plus que le « Nous » de l'in-group au « Ils » qui englobe tous « les autres », tout l'extérieur de l'inconnu et de ses institutions. Là encore, le constat exact du degré auquel les locuteurs populaires, dans cette tâche de narration et dans cette situation d'entretien, catégorisent leur discours se transforme vite 
en un diagnostic sur leur compétence logique: celle-ci semble dérisoire («impressionniste») puisque "selon toute évidence, [leur] pensée ne maîtrise pas la logique des classes $^{8} »$.

61 L'objection que l'on peut faire à ce diagnostic ne porte pas sur l'inférence qui va des récits contenus dans le corpus de Schatzman et Strauss aux structures logiques de la narration qu'ils en dégagent : tout a été sans doute analysé selon une grille de dépouillement assez fine; la performance parallèle obtenue par les enquêteurs auprès des deux groupes autorise sans doute à dire que, sur ce matériel, les locuteurs populaires maîtrisent mal, pratiquent peu certaines opérations logiques, ou si peu qu'elles ne tiennent presque pas de place dans l'engendrement des énoncés de surface. L'objection doit porter sur le terrain et la technique de mesure choisis : aurait-on abouti à des performances logiques de même forme si l'on avait choisi de situer la description sur un autre terrain que celui de la narration événementielle, ou sur des narrations consacrées à d'autres thèmes, et surtout dans d'autres situations conversationnelles?

Empruntons pour développer cette objection d'autres constats à une enquête en cours qui porte, il est vrai, sur des locuteurs paysans ou d'origine paysanne. Mais je ne les invoque ici que parce qu'ils illustrent une inversion spectaculaire des constatations dans la description de la compétence des locuteurs peu cultivés, lorsqu'on change le terrain de la mesure des compétences logiques. Il s'agit encore d'entretiens (mais dans une situation conversationnelle "à prétexte ») où les sujets sont amenés à situer des parents dans des systèmes généalogiques, au sein de leur famille ou dans d'autres familles du village. Le nombre de parents, exactement situés, bien sûr, mais surtout l'ampleur des réseaux décrits et la longueur des chaînes déductives aboutissant à identifier des parentés lointaines ou médiates, sont, on ne s'en étonnera pas, d'autant plus grands que les sujets sont plus proches de la culture vernaculaire, la différence se faisant sentir même au sein du groupe le plus populaire, au détriment des sujets les plus scolarisés ou citadinisés. La «virtuosité» (au sens labovien) manifestée dans la maîtrise de structures logiques complexes, dans la manipulation de relations, dont la plupart ne sont ni réversibles ni transitives - sans parler des règles particulières qu'introduisent dans le travail logique la considération de plusieurs « lits » successifs - change de côté dès qu'on change de terrain. Inutile d'imaginer le diagnostic sur la maîtrise de la «logique des classes » auquel conduirait l'application de cet instrument de mesure à des cadres supérieurs qui abdiquent toute velléité de penser un tel type de réseau dès le cousinage au deuxième degré.

Or nous avons bien affaire ici à des opérations du même type que celles que Schatzman et Strauss visaient quand ils voulaient les saisir à travers la maîtrise taxinomique ou l'aptitude au décentrement. L'aptitude à mémoriser les personnes ne joue qu'un rôle second puisqu'elle est justement facilitée par le jeu avec les positions, et le fait que les opérations portent sur des individus identifiés par le nom propre ne doit pas dissimuler que la tâche consiste à manipuler et à déduire, par un calcul logique, des relations dont il faut maîtriser le système et les règles pour se prononcer sans erreur. De même, c'est si peu une caractéristique générale des démarches populaires de ne pouvoir énoncer que du strict point de vue du locuteur que l'on voit ici les sujets s'acquitter de la tâche généalogique avec autant de facilité sur les parentés d'autres familles que sur la leur propre.

Qu'en conclura-t-on? Il serait évidemment puéril de crier victoire au nom des classes populaires (tel populisme n'y manque pas sur des cas analogues). Mais l'illusion de 
Schatzman et Strauss est bien la même que celle qui consisterait, sur ce nouveau matériel, à affirmer que l'influence de l'École ou les tâches de la vie citadine contribuent à abaisser le niveau d'« aptitude logique ». Les deux constats empiriques ne sont pas contradictoires, tout simplement parce qu'ils procèdent à des mesures qui inversent la familiarité des groupes avec le terrain et la situation d'effectuation de la tâche. Mais c'est bien une question méthodologique centrale à la comparaison entre classes sociales qui se trouve posée : le terrain et les conditions dans lesquels on choisit de mesurer une performance culturelle, verbale ou logique, anticipent déjà le degré de compétence que l'on aboutira à mesurer.

Comment choisir, dira-t-on? En tout cas, en évitant d'oublier les relations qui unissent différemment terrains d'observation, procédés de recueil de l'information et techniques de mesure, aux actualisations de la compétence par le comportement ou la parole selon les classes sociales. Cette sociologie des rapports entre les instruments ou les choix d'enquête et l'objet social auquel on les applique est partie constitutive de la " construction » de l'objet sociologique - dont on voit, en passant, qu'elle est déjà un travail sociologique (tout comme la "déconstruction" de l'objet préconstruit) et non n'importe quelle gymnastique formelle, théorique ou méthodologique dont l'exhibition préalable suffirait à assurer la " rupture » (il est devenu à la mode de dire «Construisez votre objet » comme on dirait : "Faites quelque chose, voyons! Montrez que vous vous bougez »). Ce minimum de vigilance suffit au moins à dissiper l'illusion qu'on pourrait repérer une fois pour toutes le "bon terrain", au sens d'un «terrain neutre» où la comparaison entre groupes ou classes pourrait enfin fonctionner idéalement, parce qu'elle n'obligerait personne à jouer sur le terrain de l'adversaire. En tout cas, pour en revenir à notre sujet, l'invite à l'« imagination sociologique » que contient la question fait apercevoir pourquoi la sociologie de la culture a si souvent fait jouer les classes populaires sur «terrain adverse»: le légitimisme est au moins autant dans ses instruments que dans sa théorie; la théorie relativiste peut encore faire des coups légitimistes sans le savoir.

Ainsi averti le projet de relativisation peut au moins conduire à diversifier les terrains et les formes de l'observation, les étendre au-delà de la géographie coutumière de l'enquête : la coutume scientifique est facilement ethnocentrique en matière de culture populaire même quand elle se nourrit des théories qui veulent décisoirement en prendre le contre-pied.

67 Mais, sur ce chemin que balise le relativisme culturel, surgit encore - notons la pour nous y refuser - l'illusion dernière du positivisme, celle qui porte à croire qu'une observation énumérative pourrait atteindre à l'exhaustivité et fonder un "vrai» bilan global: lorsqu'on a fait jouer tous les groupes sur tous les terrains, est-ce que le score final (par exemple en termes de compétence logique) ne retrouverait pas un sens? Évidemment non, puisque reste insoluble (Lévi-Strauss le disait avec force dans Race et histoire, à propos de la comparaison entre cultures) le problème de la commensurabilité des mesures, homologue du problème statistique de l'arbitraire des pondérations entre indicateurs ou indices. Il est trop facile de faire gagner qui l'on voudra par la multiplication des parties quand l'on reste maître de représenter inégalement les types de jeux; et à concevoir un championnat multijeux honnêtement équilibré, en prenant autant de terrains et de jeux familiers aux classes dominées et aux classes dominantes, on préfabrique seulement un match nul dépourvu de sens. L'invite que recèle l'inquiétude relativiste, associée à la sociologie des différences est ailleurs : inciter à ne pas ignorer 
systématiquement dans l'observation ou la mesure, trop de terrains qui sont habituels aux classes populaires et que la sociologie ne visite guère plus souvent ou pas autrement que les promeneurs des classes dominantes; ne pas mettre à tous coups à leurs pratiques ou leurs symbolismes la pondération minimum.

C. GRIGNON.- Le sort fait par Schatzman et Strauss à ce qu'ils appellent «inaptitude au décentrement" est en effet particulièrement exemplaire dans la mesure où on a l'impression d'un affrontement symétrique entre deux ethnocentrismes: l'auditeur savant déplore l'ethnocentrisme du narrateur populaire, qu'il formule en « faible aptitude au décentrement » alors que c'est la faible aptitude au décentrement de l'auditeur qui construit la faible aptitude au décentrement du narrateur.

Mais le fait que vous soyez amené à choisir le contre-exemple que vous opposez à Schatzman et Strauss dans la culture paysanne, c'est-à-dire dans une espèce très particulière de culture populaire, qui s'oppose à bien des égards à la culture ouvrière - la distance à la paysannerie étant un des principes essentiels de variation des pratiques et des goûts populaires - donne à penser qu'il serait temps de commencer à spécifier les questions que nous nous posons en fonction des différents groupes qu'on a confondus jusqu'ici sous le nom de classes populaires. Ce sera, je crois, un des objets de la séance suivante. On peut rappeler dès maintenant que la culture dominante ne fait pas le même cas de la culture paysanne et de la culture ouvrière ; l'une et l'autre, on le sait, font l'objet de traitements différents et inégaux de la part de la littérature ou de la peinture, qui jouent sur l'opposition entre l'ouvrier et le paysan, la ville et le village, l'industrie et l'artisanat. Par ailleurs, culture et classe ne sont sans doute pas dans le même rapport entre elles selon qu'il s'agit de la paysannerie ou des ouvriers : on pourrait presque dire qu'on a affaire, dans un cas, à une classe sans culture, et dans l'autre, étant donné l'ampleur de l'exode rural, à une culture sans classe. Pour en revenir au contre-exemple que vous invoquez, il me semble que la science paysanne des généalogies représente un cas extrême de la culture paysanne, dans la mesure où elle demande, pour se constituer et se transmettre, un degré élevé d'isolement et d'autonomie à la fois dans le temps et dans l'espace (l'opposition entre « Nous » et les « Autres » trouvant sa forme la plus solide et la plus ferme dans le cadre du village).

R.-M. LAGRAVE.- À propos de la diversification des terrains d'analyse, il y a souvent des matériaux qu'on ne songe pas assez à exploiter. Lorsque Rancière a fait La parole ouvrière et les luttes prolétaires, il a travaillé sur des correspondances; il a pris des lettres d'ouvriers, qui étaient une pratique ordinaire pour eux à l'époque...

71 J.-C. PASSERON.- Était-elle ordinaire? Ne l'était-elle pas? On pourrait en discuter. Tout compte fait, je ne crois pas. Mais surtout étant donné les conditions d'usage et d'exception dans lesquelles l'écriture mettait le scripteur ouvrier au XIX ${ }^{e}$ siècle, je ne suis pas sûr que ce soit un terrain où s'actualiseraient adéquatement compétences, dispositions et expressions populaires. Ce qui me paraît intéressant c'est la prédilection que le chercheur manifeste souvent pour ces terrains d'exception. N'y a-t-il pas dans la préférence systématique (je veux dire si fréquente) pour les terrains où l'on attend le moins la performance populaire sinon quelque effet de mode, du moins une recherche du chemin populiste le moins direct? Il me semble que le succès de la figure de l'ouvrier épistolier, mais tout aussi bien de celle du paysan mémorialiste (fort productif ces tempsci), procède à la fois d'une pulsion, fort respectable, de réhabilitation de la production symbolique des gens du peuple et de quelque effet subtil de l'emprise légitimiste sur nos narodniki. C'est encore un coup fourré du rapport de domination symbolique que de 
porter à croire qu'il n'y a de réhabilitation pleine et entière que celle qui rend l'illégitime légitime conformément aux habitudes contractées par le réhabilitateur au contact prolongé de la légitimité. Il faut que cessent de manquer, nous suggère-t-il, à la panoplie de la culture populaire toutes ces belles et bonnes choses que nous avons appris à priser si fort. N'ont-ils pas aussi leur art abstrait, leur avant-gardisme et, plus subtilement, jusqu'au « naïvisme » qui, fonctionnant déjà au deuxième degré dans la culture savante, l'est forcément au troisième chez eux (le facteur Cheval ou le fossoyeur Picassiette) ? Il n'est pas bon que la stratégie de recherche se voit purement et simplement relayée par l'étonnement émerveillé que ceux qui ont si peu aient finalement, pour peu qu'on veuille suffisamment l'y voir, tout ou presque tout.

Mais revenons à l'objection de Grignon qui donne un autre élan à la diversification de l'observation: elle a aussi pour tâche de casser le monolithe que représente le concept de culture dominée. "Dominer", matériellement ou symboliquement, est une relation si générique qu'elle ne permet jamais de fonder la description sur autre chose que des caractéristiques très générales - et à la limite trans-historiques - de la condition dominée. Les questions que l'on peut poser en commun à une culture ouvrière et à une culture paysanne ne sont guère que des questions « communes ». Il faut même aller plus loin dans la stratification, dans la périodisation et dans la contextualisation pour commencer à définir un protocole de recherche.

C. GRIGNON.- Tout donne à penser en effet que le degré auquel la culture populaire est réellement confrontée à la culture dominante varie en fonction des catégories sociales ou des groupes (paysans par opposition à ouvriers), des lieux ou des situations, des domaines d'activité et des types de pratiques (consommations culturelles savantes ou semi-savantes versus culture pratique), etc. On peut se demander, dans ces conditions, si ce n'est pas trop accorder au légitimisme que de faire comme si la culture dominée était toujours pénétrée, investie, hantée au même degré par la culture dominante. Ne doit-on pas supposer que la modalité au moins de cette obsession, de cette hantise, diffère selon le degré d'isolement et de protection dont bénéficient les différents groupes ou les différents univers? Selon qu'on se place dans la problématique de l'alternance ou au contraire dans la problématique de l'ambivalence, un même ensemble de pratiques, et à la limite une même observation, peuvent faire l'objet, comme le texte de Navel, de deux lectures antagonistes. Soit par exemple le cas d'un ouvrier qui occupe une partie de ses congés à faire des travaux dans son appartement ou son pavillon; à partir de l'opposition entre la vie privée, retranchée, et la vie professionnelle, exposée, entre l'usine et la maison, le travail et le temps libre, on peut décrire son activité comme l'aménagement d'une niche de vivabilité, le support de formes de sociabilité spécifiques (entraide), l'expression et l'affirmation d'un goût autonome, etc. ; on peut, au contraire, dire qu'il est doublement dominé, qu'il se fait doublement " avoir », dans la mesure où il consent un travail supplémentaire, un sur-travail, pour introduire et afficher chez lui, et encore en toc, en « simili », les emblèmes - moquette, papier peint, etc. - du goût dominant.

74 J.-C. PASSERon.- Il ne faut quand même pas oublier, lorsqu'il s'agit d'organiser ou de stabiliser les rapports entre les deux grilles de description d'un symbolisme dominé (en termes d'autonomie ou de référence à la domination, de B ou de B'), que la problématique de l'alternance entre ces deux logiques (selon les moments, les lieux, les pratiques ou les sous-groupes considérés) a le mérite de définir et d'encadrer clairement les tâches du repérage et de l'observation empiriques. Par la discrimination qu'elle impose, elle est déjà plus exigeante que les grilles, toujours distordues par quelque parti pris idéologique, qui 
convient à ne retenir d'un symbolisme dominé que ce qui est tout l'un ou tout l'autre. Avec les gros sabots de l'énumération, elle évite aussi, au moins dans un moment préalable, de subordonner toute description au problème, moins maîtrisable scientifiquement, non pas tellement du langage conceptuel permettant de dire la présence d'un signifié au cœur du signifié contraire (les mots et les schémas de la psychanalyse sont, pour le meilleur et pour le pire, à la portée de tous), mais surtout le problème de faire fonctionner ce langage comme organisateur de constats empiriques comparables et composables. Tant que ce cadre logique n'est pas hypostasié en une cartographie universelle du monde des pratiques sociales prétendant épuiser les phénomènes pour en donner le bilan global dans une carte du territoire superposable au territoire, il garde la vertu d'obliger à multiplier les constats, à distinguer les secteurs, bref de démultiplier la description : ce qui est vrai du vêtement l'est-il de l'ameublement, ce qui est vrai de la décoration de l'habitat (moralisme) l'est-il de celle de l'atelier (pin-ups), etc. Il produit des connaissances.

Mais il est vrai que cette grille de travail rencontre vite ses limites dans la nécessité d' interpréter tout constat, toute mesure : pour dire ce que veut dire un comportement, une œuvre ou un discours, vient toujours le moment où il faut accepter de montrer en une chaîne de présomptions un ensemble de constats connexes et hétérogènes. Il n'est peutêtre aucun domaine des pratiques dominées ni aucun groupe dominé où le rassemblement d'indices au service de la tâche interprétative ne permette d'énoncer vraisemblablement la présence du Même dans l'Autre et vice versa (de quelque effet de la domination symbolique dans l'autonomie et d'une forme de quant-à-soi dans la dépendance). Ce style d'interprétation des réalités sociales produit une intelligibilité théorique et les plus empiristes y recourent plus souvent qu'on ne croit, bien qu'un peu honteusement. On n'empêchera pas le sociologue qui n'a pas oublié complètement qu'il pratique une science de l'homme, d'y voir la fine pointe de l'énonciation sociologique, la " fleur » de son labeur - au sens où la théorie du Nô met dans la fleur de cet art ce qui justifie, en les faisant oublier, les cheminements laborieux de l'apprentissage de l'acteur.

Un seul exemple ici du mouvement qui conduit inévitablement l'analyse sociologique d'une problématique à l'autre. Je l'emprunte de nouveau à une culture paysanne puisque Grignon objectait à juste titre que l'art conventionnel des généalogies paysannes illustre surtout une culture vestigiale, y compris en milieu rural, qui doit à des conditions particulières de retranchement spatial une autonomie quasi parfaite de fonctionnement. Même dans ce cas-limite, il faudrait pourtant se garder de croire que l'autonomie des pratiques symboliques des individus les plus traditionnels (les plus âgés, les moins cultivés) se manifeste dans toutes leurs pratiques et sur tous les terrains. Les mêmes sujets laissent voir dans d'autres domaines de l'expression et du jugement de goût la perméabilité de leurs dispositions traditionnelles à toutes sortes d'effets de la domination symbolique des goûts citadins sur les goûts ruraux. Témoigne par exemple d'une soumission empressée aux critères du goût citadin de classe moyenne leurs pratiques d'ameublement: dans un premier temps, ils s'étaient laissé soustraire sans difficultés les fameux meubles rustiques "qui valent aujourd'hui des millions chez les antiquaires", acceptant en échange, avec plaisir et souvent le sentiment de la "bonne affaire ", les meubles en formica qui font se récrier de nostalgie (et d'intérêt frustré) leurs descendants citadinisés; mais, dans la période suivante, sous l'effet même de ces récriminations culpabilisantes et de nouveaux circuits de diffusion et d'imposition du goût (magazines, démarchage, progression des points de vente), les voilà qui rééquipent le foyer en faux rustique dont la "valeur» leur est imposée par une nouvelle vulgarisation de la 
légitimité, jusque dans les mots importés qu'ils emploient spontanément pour nommer ce qu'ils avaient exporté sous un autre nom (c'est vrai que c'est joli «le rustique»). Particulièrement caractéristique de cette ré-imitation de leur propre culture légitimée par l'imitation commerciale de leurs propres objets et leur diffusion en milieu citadin, est l'aventure de la cheminée vernaculaire, démolie avec soulagement lors du passage au chauffage au mazout, et reconstruite vingt ans après sur un modèle trans-régional (« c'est quand même plus intime, ils font tous ça maintenant »).

Alternance de la logique du quant-à-soi et de celle de la domination, alternance d'effets contrastés de forces et d'agents différents de la domination symbolique permettent de décrire, cette histoire, i. e. d'immobiliser chacune de ces phases pour la décrire. Mais ces schèmes ne font-ils pas injustice interprétative aux pratiques dominées ? L'alternance des goûts dont cette grille de description photographie l'oscillation visible ne cache-t-elle pas une ambivalence plus subtile? Lorsque les ruraux se laissent soustraire, dans les années 1950, par l'échange ou pour quelque liquidité, les vétustes tuiles « romaines» de leurs toitures qui allaient recouvrir ostentatoirement les résidences secondaires voisines, afin de les remplacer par une couverture de plaques ondulées en fibrociment, le goût cultivé qui déplorait cette « horreur » et, s'il se piquait de populisme, le dénonçait en termes de dépossessions matérielle et symbolique, ne réussissait-il pas à ignorer ethnocentriquement quelque chose du vernaculaire profond de l'évaluation et de la décision paysannes? Ne décryptaient-ils pas avec leur code de visiteurs le sens d'un environnement qui était pratiqué autrement par les autochtones: ceux-ci n'avaient jamais envisagé leurs propres toits sous l'angle du coup d'œil esthétique désintéressé, mais presque toujours sous celui de leurs inconvénients techniques ( $«$ il faut réparer sans cesse "; la " neige fait des dégâts chaque hiver »), enfin esthétiquement surmontés par la découverte du fibrociment. Et dans la reconversion, là aussi vingt ans après, au style qui fait consentir à enlever le fibrociment ondulé pour un autre ciment imitant plus fidèlement la tuile ancienne, sous la pression des leçons culturelles venues d'ailleurs et de haut (ou. tout simplement de la Protection des Sites), n'y a-t-il vraiment que palinodie imposée à des dominés s'essoufflant à suivre les goûts qu'on leur fait avoir ou leur dit de suivre? Un quant-à-soi dernier, gérant tactiquement à travers toutes ces phases, les péripéties de l'histoire et composant dans son " goût ", d'une manière irréductiblement autre, nécessité technique et disposition esthétique qui sait "en prendre et en laisser ", n'exprime-t-il pas sa distance sereine aux goûts dominants dans une docilité souriante qui n'engage pas autant, ou pour les mêmes choses, que dans les classes sociales où le goût est l'affaire principale du symbolisme de la position?

C. GriGnon.- Ce que le populisme a d'irréductiblement anti-populaire se voit en effet particulièrement bien dans la valorisation par le dilettante cultivé de ce que l'indigène rejette comme sans valeur. Comme l'écrit M. Maget,

«...l'amateur s'émeut du charme des tolérances qui poétisent une production en série artisanale, en embrumant la norme de fabrication; l'artisan au contraire s'enorgueillit d'avoir une régularité de machine, de réduire les temps de fabrication et les tolérances'. »

79 Pour en revenir au choix entre les grilles de lecture, rien ne paraît s'opposer, en effet, au choix d'une perspective strictement alternativiste tant qu'on s'en tient au niveau de l'inventaire descriptif et systématique des possessions et des pratiques des classes dominées. Le refuge, même un peu attentiste, dans l'accumulation empirique des données est après tout un bon moyen de conjurer les obsessions engendrées par la rencontre de la «Culture » et du «Peuple». Mais ne sommes-nous pas sur un terrain où l'on peut moins 
que jamais distinguer entre le moment de la description et celui de l'interprétation - entre la "fleur» et le «labeur», la "fine pointe» et les "gros sabots»? Peut-on, surtout dans le cas des classes populaires, qui n'ont pas au même degré que les classes dominantes les moyens de réaliser leurs goûts, disjoindre l'étude des consommations et des pratiques de l'étude du rapport que les sujets ou les groupes entretiennent avec leurs consommations et leurs pratiques ? Et là, les choses se compliquent ; il devient beaucoup plus gênant de renoncer à vouloir voir et dévoiler les contradictions - l'ambivalence - que recèle, au moins potentiellement, chaque possession, chaque consommation, chaque pratique. Comment ne pas dire et ne pas dire d'emblée : oui, ils achètent ceci, mais c'est faute de pouvoir acheter cela, ou encore : oui, ils font ainsi, mais dans le moment même où ils le font, n'ont-ils pas honte de le faire ? Comment renoncer à montrer de quoi est fait - envie, ressentiment, mauvaise foi, humiliations, frustrations, mépris des autres retourné contre soi, etc. - le goût que les gens ont ou croient avoir pour ce qu'ils ont et pour ce qu'ils font, pour ce qu'on leur fait avoir et pour ce qu'on leur fait faire?

Le choix de l'une ou l'autre de ces perspectives n'engage sans doute pas seulement des représentations globales et ultimes de la "société » (équivalent pour les sociologues des mythes cosmiques que mobilisent les astronomes et les physiciens quand il essaient d'imaginer les origines et le devenir de l'univers) ni, à la limite, des philosophies sociales opposées, relativiste et "démocratique » dans un cas, hiérarchico-élitiste dans l'autre, mais des orientations et des postures épistémologiques bien différentes - des manières différentes de faire et d'écrire de la sociologie. Dans la mesure où elle se cramponne à la perspective alternativiste qui, en délimitant pour elle un terrain spécifique, lui ouvre une carrière empirique et lui permet de faire donner à plein les techniques du constat et de la mesure, la sociologie des cultures populaires regarde franchement du côté de la science, mais de la science définie par référence au modèle des sciences expérimentales. Dans la mesure où elle choisit au contraire l'ambivalence, et où, se donnant une tout autre définition du " caché » et de la " recherche », elle part du principe que les façons d'être les plus autosuffisantes et les plus autosatisfaisantes en apparence doivent être considérées comme des symptômes et dissimulent des secrets qu'il lui appartient de débusquer, elle louche vers ce que l'on appelle les «théories du soupçon »; soit, pour prendre des repères connus, Claude Bernard et Popper du côté de l'alternance, et, du côté de l'ambivalence, la triade Marx, Freud et Nietzsche. On voit que la sociologie des cultures populaires a au moins un problème en commun avec la sociologie de la culture dominante, et un problème de taille: comment animer ces constats descriptifs, ces données, ces tableaux, ces inventaires - bref ce «matériel »- par cet « esprit » qui « dit toujours non"? Comment contrôler la malignité et la perversité de ce "démon", toujours porté à ruser avec les contraintes que lui impose le travail empirique, à tricher avec les règles de la méthode et à se livrer, sous le masque de la science, au délire d'interprétation qui le travaille? Comment, dans le cas précis qui nous occupe, faire apparaitre le degré auquel et la manière dont la culture dominante «investit » les pratiques des dominés si l'on n'introduit pas l'esprit de l'ambivalence dès le niveau de l'enquête et de l'élaboration des outils? Mais comment savoir alors si ce que l'on croit déceler habite réellement l'«inconscient» du goût populaire, si les significations auxquelles aboutit l'analyse ne sont pas au contraire des artefacts purs et simples, le produit d'une mise en confrontation forcée et obsessionnelle des cultures, voire la projection des fantasmes de l'interprète ? Comment savoir si le « contenu latent » qu'on se donne ainsi la possibilité de dévoiler est bien la traduction intégrale, véridique et 
adéquate des goûts et des désirs enfermés dans les pratiques et dans le discours «manifestes » des dominés?

\section{NOTES}

1. Cf. G. Navel, Travaux, Paris, Gallimard, p. 95-97 (« Folio »), document joint [pdf].

2. Voir, entre autres, de Michel Ragon, L'histoire de la littérature prolétarienne en France. Littérature ouvrière, littérature paysanne, littérature d'expression populaire, Paris, A. Michel, 1974.

3. P. Bourdieu, J.-C. Chamboredon, J.-C. Passeron, eds, Le métier de sociologue. Préalables épistémologiques, Paris-Berlin, Mouton/Paris, EHESS, 4 éd., 1983, p. 223-237 de la nouvelle édition.

4. Ibid., p. 223.

5. Ibid., p. 224.

6. Ibid.

7. Ibid., p. 229.

8. Ibid.

9. M. Maget, « Problèmes d'ethnographie européenne », in J. Poirier, ed., Ethnologie générale, Paris, Gallimard, 1968, p. 1247-1338 (« Encyclopédie de la Pléiade » 24). 